\title{
Application of MJO Simulation Diagnostics to Climate Models
}

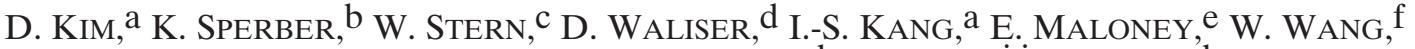 \\ K. Weickmann, g J. Benedict, ${ }^{\mathrm{e}}$ M. Khairoutdinov, ${ }^{\text {h }}$ M.-I. Lee, ${ }^{\mathrm{i}, \mathrm{j}}$ R. NeAle, ${ }^{\mathrm{k}}$ M. SuARez, ${ }^{\mathrm{f}}$ \\ K. THAYER-CALDER, ${ }^{\mathrm{e}}$ AND G. ZHANG ${ }^{1}$ \\ a School of Earth and Environmental Sciences, Seoul National University, Seoul, South Korea \\ ${ }^{\mathrm{b}}$ Lawrence Livermore National Laboratory, PCMDI, Livermore, California \\ c NOAA/Geophysical Fluid Dynamics Laboratory, Princeton, New Jersey \\ d Jet Propulsion Laboratory, California Institute of Technology, Pasadena, California \\ e Department of Atmospheric Science, Colorado State University, Fort Collins, Colorado \\ $\mathrm{f}$ NOAA/National Centers for Environmental Prediction, Camp Springs, Maryland \\ $\mathrm{g}$ Physical Sciences Division, NOAA/Earth System Research Laboratory, Boulder, Colorado \\ $\mathrm{h}$ Institute for Terrestrial and Planetary Atmospheres, Stony Brook University, Stony Brook, New York \\ i NASA Goddard Space Flight Center, Greenbelt, Maryland \\ j Goddard Earth Sciences and Technology Center, University of Maryland, Baltimore County, Baltimore, Maryland \\ k National Center for Atmospheric Research, Boulder, Colorado \\ ${ }^{1}$ Scripps Institution of Oceanography, La Jolla, California
}

(Manuscript received 2 February 2009, in final form 14 May 2009)

\begin{abstract}
The ability of eight climate models to simulate the Madden-Julian oscillation (MJO) is examined using diagnostics developed by the U.S. Climate Variability and Predictability (CLIVAR) MJO Working Group. Although the MJO signal has been extracted throughout the annual cycle, this study focuses on the boreal winter (November-April) behavior. Initially, maps of the mean state and variance and equatorial space-time spectra of $850-\mathrm{hPa}$ zonal wind and precipitation are compared with observations. Models best represent the intraseasonal space-time spectral peak in the zonal wind compared to that of precipitation. Using the phasespace representation of the multivariate principal components (PCs), the life cycle properties of the simulated MJOs are extracted, including the ability to represent how the MJO evolves from a given subphase and the associated decay time scales. On average, the MJO decay ( $e$-folding) time scale for all models is shorter $(\sim 20-$ 29 days) than observations ( $\sim 31$ days). All models are able to produce a leading pair of multivariate principal components that represents eastward propagation of intraseasonal wind and precipitation anomalies, although the fraction of the variance is smaller than observed for all models. In some cases, the dominant time scale of these PCs is outside of the 30-80-day band.

Several key variables associated with the model's MJO are investigated, including the surface latent heat flux, boundary layer $(925 \mathrm{hPa})$ moisture convergence, and the vertical structure of moisture. Low-level moisture convergence ahead (east) of convection is associated with eastward propagation in most of the models. A few models are also able to simulate the gradual moistening of the lower troposphere that precedes observed MJO convection, as well as the observed geographical difference in the vertical structure of moisture associated with the MJO. The dependence of rainfall on lower tropospheric relative humidity and the fraction of rainfall that is stratiform are also discussed, including implications these diagnostics have for MJO simulation. Based on having the most realistic intraseasonal multivariate empirical orthogonal functions, principal component power spectra, equatorial eastward propagating outgoing longwave radiation (OLR), latent heat flux, low-level moisture convergence signals, and vertical structure of moisture over the Eastern Hemisphere, the superparameterized Community Atmosphere Model (SPCAM) and the ECHAM4/ Ocean Isopycnal Model (OPYC) show the best skill at representing the MJO.
\end{abstract}

Corresponding author address: Daehyun Kim, School of Earth and Environmental Sciences, Seoul National University, Seoul 151-747, South Korea.

E-mail: kim@climate.snu.ac.kr

DOI: 10.1175/2009JCLI3063.1 


\section{Introduction}

More than three decades have passed since R. Madden and P. Julian published their pioneering discovery of tropical intraseasonal variability (Madden and Julian 1971, 1972). Since then, many studies have been devoted to understanding the Madden-Julian oscillation (MJO) (e.g., Madden and Julian 1994; Zhang 2005) and predicting it using statistical and dynamical methods (Jones et al. 2000; Lo and Hendon 2000; Wheeler and Weickmann 2001; Jones et al. 2004; Seo et al. 2005; Waliser 2006a,b; Vitart et al. 2007; Jiang et al. 2008). The MJO has been shown to impact a wide variety of climate phenomena across different spatial and temporal scales. Some examples include the onset and break of the Indian and Australian summer monsoons (e.g., Yasunari 1979; Wheeler and McBride 2005), the formation of tropical cyclones (e.g., Liebmann et al. 1994; Maloney and Hartmann 2000a,b; Bessafi and Wheeler 2006), and the onset of some El Niño events (e.g., Takayabu et al. 1999; Bergman et al. 2001; Kessler 2001). Hence, it is not possible to fully comprehend the above climate system components without knowledge of the MJO and its interactions with them (Lau and Waliser 2005). Moreover, in a practical sense, accurate simulations and skillful predictions of the above phenomena may be difficult without a realistic representation of the MJO.

Numerous multimodel MJO intercomparison studies have been published over the past decade or so (Slingo et al. 1996; Waliser et al. 2003; Lin et al. 2006; Zhang et al. 2006; Sperber and Annamalai 2008). The most significant message from these studies is that GCMs continue to struggle to represent the MJO. Slingo et al. (1996) examined tropical intraseasonal variability using atmospheric GCM simulations forced by observed monthly mean sea surface temperature (SST). They showed that the Atmospheric Model Intercomparison Project (AMIP) models were not able to simulate the observed 30-70-day spectral peak of the planetary-scale (zonal wavenumber 1) equatorial 200-hPa velocity potential. Lin et al. (2006) analyzed MJO variability in 14 Coupled Model Intercomparison Project-3 (CMIP3) models that were a part of the Intergovernmental Panel for Climate Change (IPCC) Assessment Report 4 (AR4) and showed that only two models had MJO variance comparable to observations but that many other MJO features were lacking realism. Regarding boreal summer intraseasonal variability, Waliser et al. (2003) analyzed AGCM simulations gathered by the International Climate Variability and Predictability (CLIVAR) monsoon panel. In their results, models did not realistically simulate eastward and northward propagation of precipitation seen in the observations. Recently, Sperber and Annamalai (2008) noted im- provement in representing these aspects of the boreal summer intraseasonal variability in the CMIP3 models, especially the equatorial eastward propagation. However, much work remains to improve the MJO in climate models.

The aforementioned multimodel studies attempted to provide insight into what is important for MJO simulation by comparing the different physical parameterizations employed by models of differing MJO skill, though conflicting results arose. For example, Slingo et al. (1996) found that convection schemes closed on buoyancy tended to have stronger MJO variability, whereas Lin et al. (2006) suggested that models with moisture convergence closure had better MJO variability. This contradictory finding suggests that the ability of a GCM to simulate the MJO does not depend uniquely on its convective parameterization. Rather, it depends upon the complex interactions of convection with other physical processes in the model.

Even so, past studies have provided insight into the types of atmosphere model changes that lead to improved MJO simulations. These include 1) employing inhibition mechanisms associated with cumulus convection (Tokioka et al. 1988; Wang and Schlesinger 1999; Lee et al. 2001; Maloney and Hartmann 2001; Maloney 2002; Lee et al. 2003; Zhang and Mu 2005a; Lin et al. 2008), 2) coupling to ocean models (Waliser et al. 1999; Hendon 2000; Kemball-Cook et al. 2002; Inness and Slingo 2003; Fu and Wang 2004; Sperber et al. 2005; Marshall et al. 2008), 3) improving the quality of the mean state (e.g., Inness and Slingo 2003; Sperber et al. 2005), and 4) increasing vertical resolution (Inness et al. 2001; Jia et al. 2008). With regard to type 1 , by suppressing premature activation of deep convection, a model's intraseasonal variability and MJO tend to be improved. Additionally, a more realistic MJO may arise through an improved representation of downdrafts and rain re-evaporation (Maloney and Hartmann 2001) and modified convective closures (Zhang and Mu 2005a). Regarding types 2 and 3, the majority of studies find air-sea coupling to be beneficial for the simulation of the MJO, typically improving the periodicity and organization of MJO convection. However, MJO improvement due to air-sea interaction is predicated upon representing the proper phasing of surface flux exchanges and retaining a realistic mean state. In particular, simulating a realistic near-surface basic state westerly flow in the Indian and west Pacific Oceans appears to be important for generating a realistic MJO. Vertical resolution, type 4, has been shown to be important for MJO simulation as it improves the simulation of the trimodal distribution of clouds (Inness et al. 2001) that is seen in observations (Johnson et al. 1999). 
TABLE 1. Description of participating models.

\begin{tabular}{|c|c|c|c|c|c|}
\hline Model & $\begin{array}{l}\text { Horizontal } \\
\text { resolution }\end{array}$ & $\begin{array}{l}\text { Vertical resolution } \\
\quad \text { (top level) }\end{array}$ & Cumulus parameterization & Integration & Reference \\
\hline CAM3.5-NCAR & $1.9^{\circ}$ lat $\times 2.5^{\circ}$ lon & $26(2.2 \mathrm{hPa})$ & $\begin{array}{l}\text { Mass flux (Zhang } \\
\text { and McFarlane 1995, with } \\
\text { entrainment-based closure) }\end{array}$ & $\begin{array}{l}20 \text { yr } 1 \text { Jan } 1986- \\
31 \text { Dec } 2005\end{array}$ & $\begin{array}{l}\text { Neale et al. } \\
\quad(2008)\end{array}$ \\
\hline CAM3z-SIO & $\mathrm{T} 42\left(2.8^{\circ}\right)$ & $26(2.2 \mathrm{hPa})$ & $\begin{array}{l}\text { Mass flux (Zhang and McFarlane } \\
\text { 1995, with free tropospheric } \\
\text { quasi-equilibrium closure) }\end{array}$ & $\begin{array}{l}15 \text { yr } 29 \text { Jan } 1980- \\
23 \text { Jul } 1995\end{array}$ & $\begin{array}{l}\text { Zhang and } \mathrm{Mu} \\
\text { (2005b) }\end{array}$ \\
\hline CFS*-NCEP & $\mathrm{T} 62\left(1.8^{\circ}\right)$ & $64(0.2 \mathrm{hPa})$ & Mass flux (Hong and Pan 1998) & $20 \mathrm{yr}$ & $\begin{array}{l}\text { Wang et al. } \\
\text { (2005) }\end{array}$ \\
\hline CM2.1*-GFDL & $2^{\circ}$ lat $\times 2.5^{\circ}$ lon & $24(4.5 \mathrm{hPa})$ & $\begin{array}{l}\text { Mass flux (RAS, Moorthi and } \\
\text { Suarez 1992) }\end{array}$ & $20 \mathrm{yr}$ & $\begin{array}{l}\text { Delworth et al. } \\
\text { (2006) }\end{array}$ \\
\hline $\begin{array}{l}\text { ECHAM4/ } \\
\text { OPYC*-MPI }\end{array}$ & $\mathrm{T} 42\left(2.8^{\circ}\right)$ & $19(10 \mathrm{hPa})$ & $\begin{array}{l}\text { Mass flux (Tiedtke 1989), } \\
\text { adjustment closure (Nordeng 1994) }\end{array}$ & $20 \mathrm{yr}$ & $\begin{array}{l}\text { Roeckner et al. } \\
\text { (1996); Sperber } \\
\text { et al. (2005) }\end{array}$ \\
\hline GEOS5-NASA & $1^{\circ}$ lat $\times 1.25^{\circ}$ lon & $72(0.01 \mathrm{hPa})$ & $\begin{array}{l}\text { Mass flux (RAS, Moorthi } \\
\text { and Suarez 1992) }\end{array}$ & $\begin{array}{l}12 \text { yr } 1 \text { Dec } 1993- \\
30 \text { Nov } 2005\end{array}$ & $\begin{array}{l}\text { Rienecker } \\
\text { et al. (2008) }\end{array}$ \\
\hline SNU-SNU & $\mathrm{T} 42\left(2.8^{\circ}\right)$ & $20(10 \mathrm{hPa})$ & Mass flux (Numaguti et al. 1995) & $\begin{array}{l}20 \text { yr } 1 \text { Jan } 1986- \\
31 \text { Dec } 2005\end{array}$ & Lee et al. (2003) \\
\hline SPCAM-CSU & $\mathrm{T} 42\left(2.8^{\circ}\right)$ & $26(3.5 \mathrm{hPa})$ & $\begin{array}{l}\text { Superparameterization } \\
\quad \text { (Khairoutdinov and Randall 2001) }\end{array}$ & $\begin{array}{l}19 \text { yr } 1 \text { Oct } 1985- \\
25 \text { Sep } 2005\end{array}$ & $\begin{array}{l}\text { Khairoutdinov } \\
\text { et al. (2005) }\end{array}$ \\
\hline
\end{tabular}

* Coupled model.

Since no uniform set of diagnostics has been used for assessing the quality of MJO simulations, it is tough to objectively determine the degree of improvement the modeling community has attained in simulating the MJO. With this in mind, U.S. CLIVAR established the Madden-Julian Oscillation Working Group (MJOWG). A major goal of the MJOWG has been the development of a standardized set of diagnostics to evaluate MJO simulation in climate models (CLIVAR Madden-Julian Oscillation Working Group 2008, hereafter CL-MJOWG08; http://www.usclivar.org/mjo.php). The MJOWG is encouraging the modeling community to apply this hierarchy of diagnostics to their simulations to allow for a systematic comparison with other models. This paper is the first attempt to apply these diagnostics to climate model simulations. It is hoped that the current study will be the baseline for future intercomparison studies and that this evaluation will be helpful in providing a more robust understanding of the MJO to aid future model development.

The models to which the diagnostics are applied are introduced in section 2. In section 3, the mean state, variance maps, and wavenumber-frequency spectra are examined. In section 4, the combined empirical orthogonal function (EOF) method of Wheeler and Hendon (2004) is used to investigate each model's own MJO and its life cycle. The possible reasons for the diversity of simulations and deficiencies in each model's MJO simulation are discussed in section 5, and section 6 contains the summary and conclusions.

\section{Model simulations and validation data}

\section{a. Participating models}

The three coupled and five uncoupled GCM simulations used in this study were provided by MJOWG members and other interested parties. Basic aspects of the model configurations are given in Table 1 (with more detailed descriptions available online at http://climate. snu.ac.kr/mjo_diagnostics/index.htm). The models have various horizontal (from $2.8^{\circ}$ to $1^{\circ}$ ) and vertical (from 19 to 72 levels) resolutions in their atmospheric components. Seven of the models are conventional GCMs in which convection and clouds are parameterized, while one model, the superparameterized Community Atmosphere Model (SPCAM), utilizes embedded twodimensional cloud-resolving models for these processes (Khairoutdinov et al. 2005). The conventional GCMs all use mass-flux-type convection schemes in which the clouds are represented by single or multiple updrafts and downdrafts with the assumption of steady-state clouds. These schemes have closures based on the release of convective available potential energy (CAPE, or cloud work function) when the parcel near the cloud base is lifted to the level of neutral buoyancy. Typically, this method is based on "quasi-equilibrium" theory (Arakawa and Schubert 1974). In the theory, convection (subgrid scale) quickly responds to large-scale (grid scale) forcing, with the release of CAPE (or cloud work function) triggered at a specified critical value. Two types of convective trigger functions are implemented in the models 
analyzed herein. The Tokioka modification (Tokioka et al. 1988), which suppresses convective plumes with entrainment rates less than a threshold that varies inversely with planetary boundary layer (PBL) depth, is implemented in CM2.1, GEOS5, and SNU.

In that modification, threshold value is defined as follows:

$$
\mu_{\min }=\frac{\alpha}{D},
$$

where $D$ is the depth of the planetary boundary layer and $\alpha$ is a nonnegative constant. The constant $\alpha$ in Eq. (1), which determines the strength of triggering, is largest in SNU (0.1) compared to that of CM2.1 (0.025) and GEOS5 (0.05). CAM3z and GEOS5 use a critical relative humidity $(\mathrm{RH})$ value (Wang and Schlesinger 1999) at the parcel lifting level (CAM3z, 80\%) and lifting condensation level (GEOS5, 30\%), respectively. CAM3z uses a modified closure compared to the standard CAM (Zhang and Mu 2005b), called free tropospheric quasi-equilibrium, in which convection removes CAPE generated by free tropospheric processes. CAM3.5 uses a modified calculation of CAPE whereby the reference parcel calculation is allowed to entrain (Neale et al. 2008).

Of the coupled models evaluated here, ECHAM4/ OPYC employs annual mean flux adjustment of heat and moisture to help maintain a realistic mean state. (Details of the flux adjustment procedure are described in Sausen et al. 1988.) In the case of the ECHAM4 model, Sperber et al. (2005) demonstrated that improved MJO performance was associated with reduced error in the time mean state due to flux adjustment and that this was as important as coupling to an ocean for yielding more coherent MJOs.

\section{b. Observation data}

We validate the simulations against the Advanced Very High Resolution Radiometer (AVHRR) outgoing longwave radiation (OLR) (Liebmann and Smith 1996), which is a proxy for convective activity. We use rainfall from the Climate Prediction Center Merged Analysis of Precipitation (CMAP) (Xie and Arkin 1997) and the Global Precipitation Climatology Project (GPCP) (Huffman et al. 2001). For monthly total and stratiform rainfall amounts we use the 3A25 product from the Tropical Rainfall Measuring Mission (TRMM) (Kummerow et al. 2000). The upper (200 hPa) and lower $(850 \mathrm{hPa})$ tropospheric zonal winds are from National Centers for Environmental Prediction (NCEP)-National Center for Atmospheric Research (NCAR) reanalysis data (Kalnay et al. 1996). The structures of specific humidity, surface latent heat flux, and 925-hPa moisture convergence based on the 40-yr European Centre for Medium-Range Weather Forecasts (ECMWF) ReAnalysis (ERA-40) (Uppala et al. 2005) are included in our analysis since Tian et al. (2006) indicated possible shortcomings in the MJO-relevant specific humidity fields from the NCEP-NCAR reanalysis. For the surface latent heat flux we also use the objectively analyzed air-sea fluxes (OAFlux) from Yu and Weller (2007).

A wider variety of data sources have been employed to assess observational uncertainty, though their presentation is beyond the scope of this paper. These additional diagnostics, which support the conclusions of this paper, are available via the MJO Working Group Web site (http://www.usclivar.org/mjo.php) or more directly from the model analysis Web site (http:// climate.snu.ac.kr/mjo_diagnostics/index.htm).

\section{Diagnostic strategy and basic diagnostics}

\section{a. Diagnostic strategy}

The MJOWG has assembled two levels of MJO diagnostics of increasing complexity, plus the evaluation of mean state variables that have been implicated as being directly related to MJO simulation skill (CLMJOWG08). Although the MJOWG developed diagnostics for both boreal summer and winter, for the sake of brevity we will concentrate only on the boreal winter season (November to April). However, diagnostics of boreal summer intraseasonal variability (May to October) are also presented and discussed in CL-MJOWG08 and illustrated on the simulation diagnostics Web site. As a crucial starting point, the mean state of relevant variables, some of which have been discussed in section 1 , are first validated. Level-1 diagnostics assess the dominant spatial and temporal scales, as well as propagation direction of precipitation and 850-hPa zonal wind. Because these diagnostics only provide a general evaluation in terms of mean state and broadband intraseasonal variability, level-2 diagnostics are employed to extract and evaluate the MJO using multivariate EOF analysis. Defining MJO phases from the leading principal components (PCs), the temporal persistence of model MJO amplitude as a function of subphase is compared with observations. Finally, MJO life cycle composites of moist variables are derived to gauge the realism of each model's simulated fields and gain insight into the mechanism by which the MJO is maintained.

\section{b. Mean state}

Figure 1 shows the mean state of the 850 -hPa zonal wind and precipitation. Although some pronounced mean state biases exist, both models and observations suggest that high mean precipitation $\left(>11 \mathrm{~mm}\right.$ day $\left.^{-1}\right)$ in the west Pacific is associated with the eastward 
a) CMAP/NCEP1

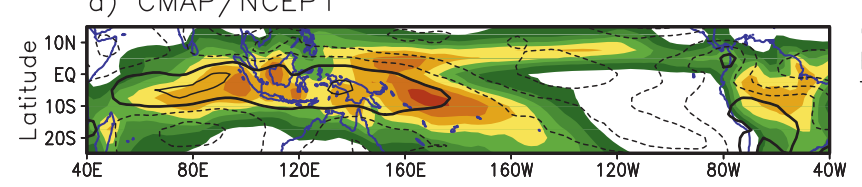

Contour Unit : $\left[\mathrm{m} \mathrm{s}^{-1}\right]$

Plot: $3 \mathrm{~m} \mathrm{~s}^{-1}$ interval

Thick solid : $0 \mathrm{~m} \mathrm{~s}^{-1}$

b) $\mathrm{CAM} 3.5$

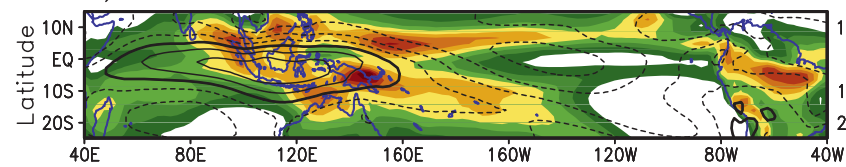

c) $\mathrm{CAM}_{3} \mathrm{z}$

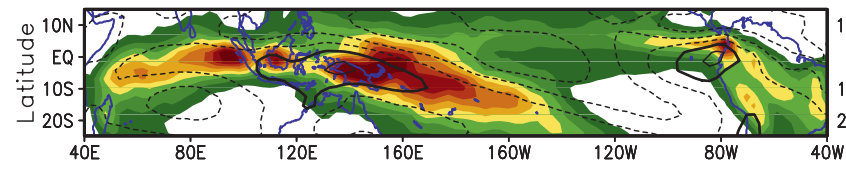

d) CFS

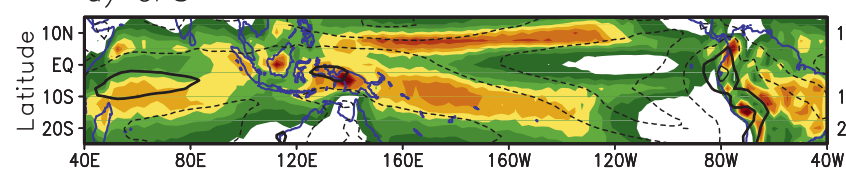

e) CM2.1

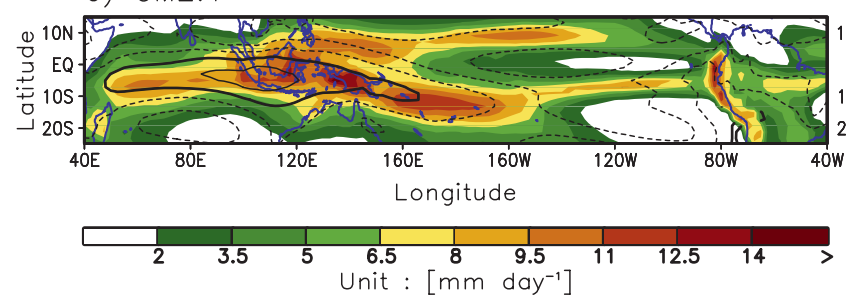

f) $\mathrm{ECHAM} 4 / \mathrm{OPYC}$

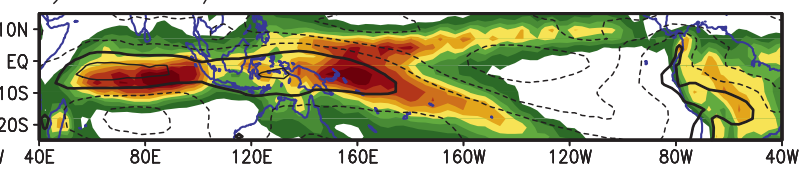

g) GEOS5



h) SNU

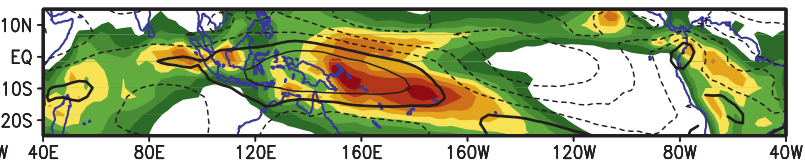

i) SPCAM



FIG. 1. November-April mean precipitation $\left(\mathrm{mm} \mathrm{day}^{-1}\right.$ ) (shaded) and 850 -hPa zonal wind ( $\mathrm{m} \mathrm{s}^{-1}$ ) (contoured) of (a) CMAP/NCEP/ NCAR, (b) CAM3.5, (c) CAM3z, (d) CFS, (e) CM2.1, (f) ECHAM4/OPYC, (g) GEOS5, (h) SNU, and (i) SPCAM. Contours of mean $850-\mathrm{hPa}$ zonal wind are plotted every $3 \mathrm{~m} \mathrm{~s}^{-1}$ with the zero line represented by a thick solid line.

extension of the westerly zonal wind into that basin. Over the tropical western Pacific Ocean the mean state of the $850-\mathrm{hPa}$ zonal wind has been shown to be indicative of the ability of a model to represent MJO convection over this region (e.g., Inness et al. 2003; Sperber et al. 2005). Of the models analyzed herein, only CFS does not bear out this relationship, although in this model the strongest $\mathrm{MJO}$ convective signal is incorrectly located over the Eastern Hemisphere.

The results from the mean state diagnostics are summarized in Fig. 2. The scatter diagrams of pattern correlation versus normalized root-mean-square error (NRMSE) over the west Pacific and Indian Oceans are used as metrics to assess mean state skill. Higher pattern correlations and lower NRMSE are desirable. There is no model that is the best for all the variables. For example, ECHAM4/OPYC, which uses annual mean flux adjustment of heat and moisture, shows superior skill in simulating low-level wind (Fig. 2c), though it is in the middle of the populations for OLR (Fig. 2b) and upperlevel wind (Fig. 2d).

\section{c. 20-100-day filtered variance}

To see how the magnitude and geographical distribution of intraseasonal variability are simulated, we show maps of the 20-100-day filtered variance of $U_{850}$ and precipitation (Fig. 3). In observations (Fig. 3a), the $U_{850}$ and precipitation variance maxima are located in the eastern Indian Ocean, western Pacific, and south of the Maritime Continent region. The intraseasonal variability of both $U_{850}$ and precipitation is weak over the Maritime Continent. These attributes are most realistically represented in CAM3z, ECHAM4/OPYC, SNU, and SPCAM (Figs. 3c,f,h,i). Based on the pattern correlations in Figs. 2e,f, CAM3z and SPCAM (Figs. 3c,i) demonstrate an improved intraseasonal variance pattern compared to the current standard version of the model, CAM3.5 (Fig. 3b), although they have variance 

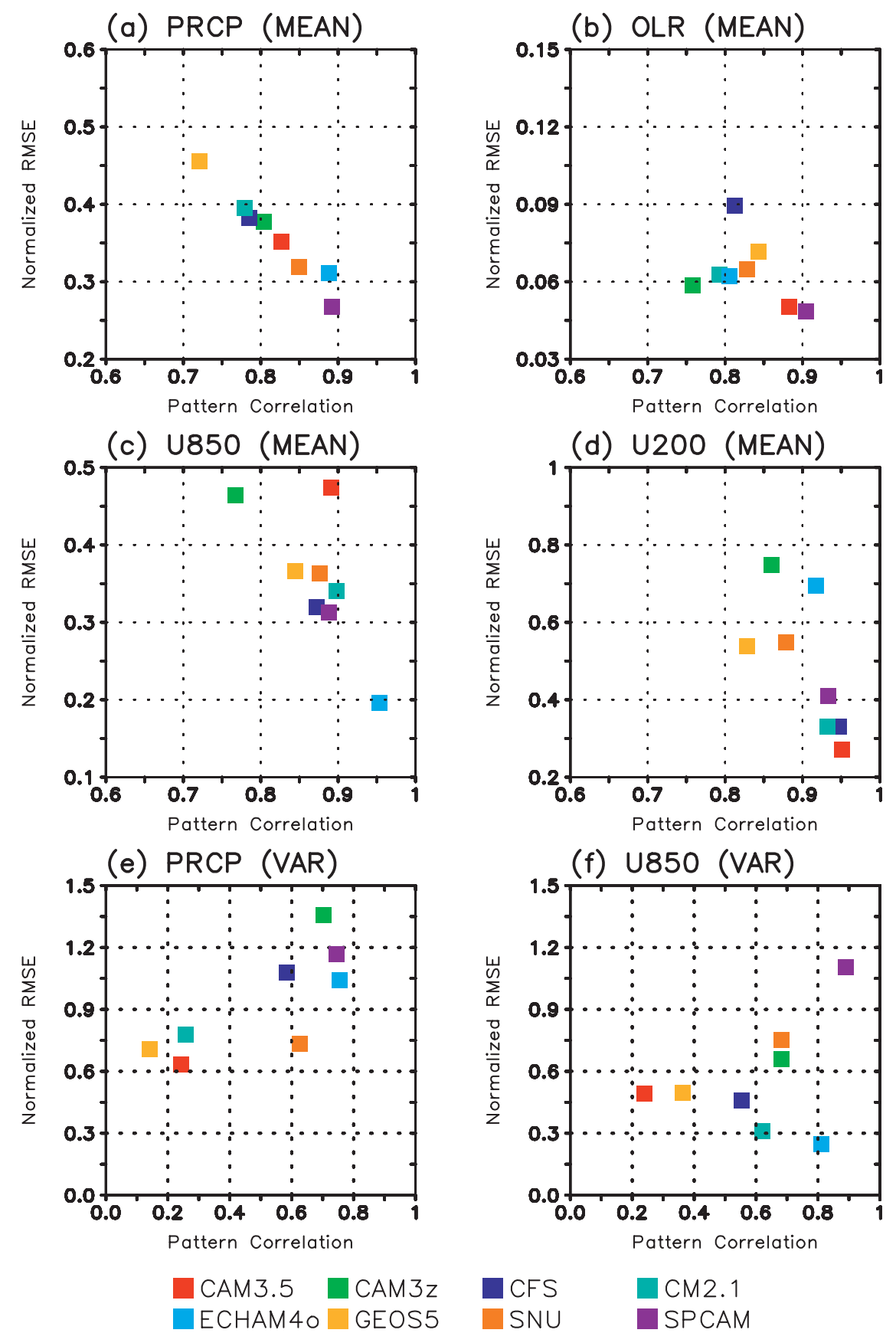

FIG. 2. Scatterplot of pattern correlation and normalized RMSE for November-April mean (a) precipitation, (b) outgoing longwave radiation, (c) 850-hPa and (d) 200-hPa zonal wind, and 20-100-day filtered variance map of (e) precipitation and (f) 850-hPa zonal wind. The region for pattern correlation and normalized RMSE is $25^{\circ} \mathrm{S}-15^{\circ} \mathrm{N}, 0^{\circ}-360^{\circ} \mathrm{E}$. RMSE is normalized by one standard deviation of the observed value.

much higher than observed. Earlier versions of the CAM model also exhibited difficulty in simulating intraseasonal variations (Sperber 2004), and other modifications of the convection scheme in CAM have led to improved intraseasonal behavior (Maloney and Hartmann
2001; Liu et al. 2005; Zhang and Mu 2005a). Both GEOS-5 and CAM3.5 have weaker than observed precipitation variance.

As noted in Figs. 2e and 2f, a comparison of Figs. 1 and 3 indicates that the observed pattern correlation between 
a) $\mathrm{CMAP} / \mathrm{NCEP}$

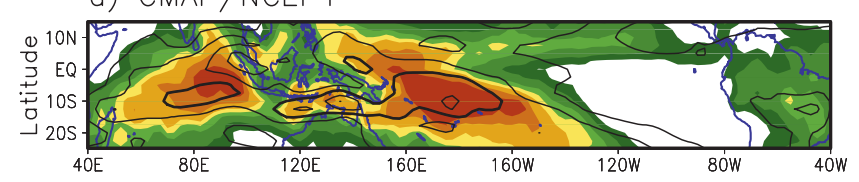

Contour Unit : $\left[\mathrm{m}^{2} \mathrm{~s}^{-2}\right]$

Plot: $3 \mathrm{~m}^{2} \mathrm{~s}^{-2}$ interval

Thick solid : $9 \mathrm{~m}^{2} \mathrm{~s}^{-2}$ b) $\mathrm{CAM} 3.5$

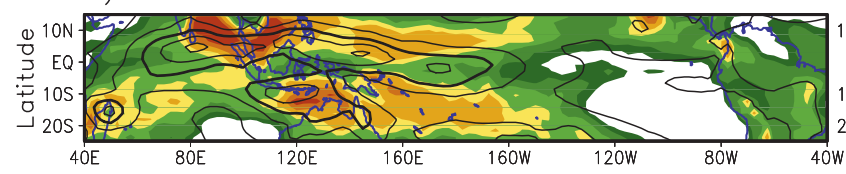

c) $\mathrm{CAM}_{3} \mathrm{z}$

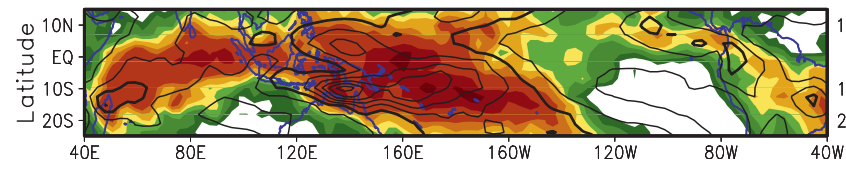

d) CFS

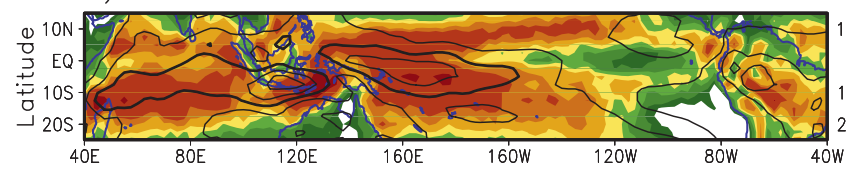

e) $\mathrm{CM} 2.1$



f) ECHAM 4/OPYC

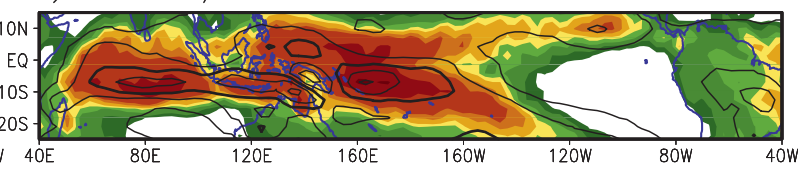

g) GEOS5

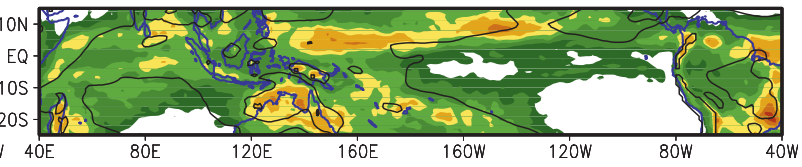

h) SNU

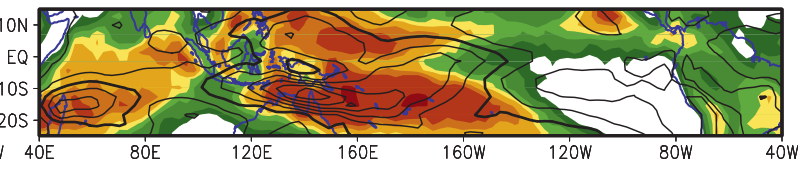

i) SPCAM

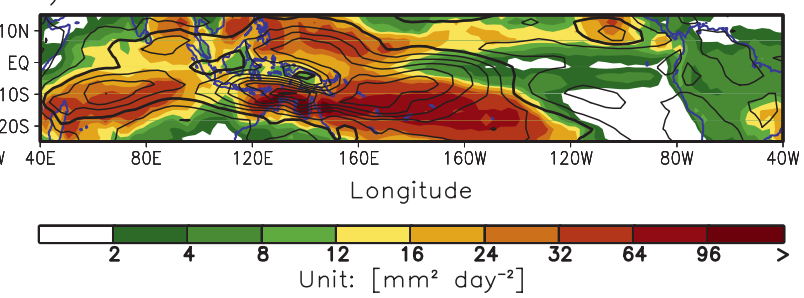

FIG. 3. As in Fig. 1 but for variance of 20-100-day bandpass filtered precipitation $\left(\mathrm{mm}^{2} \mathrm{day}^{-2}\right)$ and 850 -hPa zonal wind $\left(\mathrm{m}^{2} \mathrm{~s}^{-2}\right)$. Contours of $850-\mathrm{hPa}$ zonal wind variance are plotted every $3 \mathrm{~m}^{2} \mathrm{~s}^{-2}$ with the $9 \mathrm{~m}^{2} \mathrm{~s}^{-2}$ line represented by the thick solid line.

the mean state and intraseasonal variance is generally higher for precipitation $(0.78)$ than $U_{850}(0.37)$. In comparison, averaged values over the simulations are 0.79 (precipitation) and $0.29\left(U_{850}\right)$, suggesting that models can reproduce this behavior. Additionally, there is a correspondence between the strength of simulated South Pacific convergence zone (SPCZ) and the strength of intraseasonal variability. For CAM3z, CM2.1, ECHAM4/ OPYC, SNU, and SPCAM, the SPCZ rainfall is larger than observed, and these models all have stronger than observed intraseasonal variance. This result is consistent with the model results of Slingo et al. (1996), with the SPCZ signal possibly being related to Rossby wave propagation induced by MJO convection (Matthews et al. 1996).

\section{d. Wavenumber-frequency spectra}

In Fig. 4 we use equatorial wavenumber-frequency plots (Hayashi 1979) of precipitation and $U_{850}$ to isolate the characteristic spatial and temporal scales on which variability is organized. Consistent with the results of previous studies (Weickmann et al. 1985; Kiladis and Weickmann 1992; Zhang et al. 2006), the dominant spatial scale of precipitation in observations is zonal wavenumbers 1 to 3 and for $U_{850}$ it is zonal wavenumber 1 for periods of 30-80 days (Fig. 4a). These scales distinguish the MJO from other convectively coupled equatorial waves (Wheeler and Kiladis 1999).

For $U_{850}$, ECHAM4/OPYC produces a spectrum similar to observation (Fig. 4f), whereas CFS and SPCAM overestimate the power for periods of 30 to 80 days (Figs. $4 \mathrm{~d}$ and $4 \mathrm{i}$ ). For CAM3.5 and CM2.1, the eastward propagating power tends to be concentrated at low frequencies (period $>80$ days, Figs. 4b and 4e). Most models (CAM3.5, CFS, CM2.1, ECHAM4/OPYC, GEOS5, and SNU) are less successful at representing the 30-80-day spectral peak for precipitation than that of $U_{850}$. Consistent with Zhang et al. (2006), these results suggest a lack of coherence between the simulation of intraseasonal precipitation and $U_{850}$. 

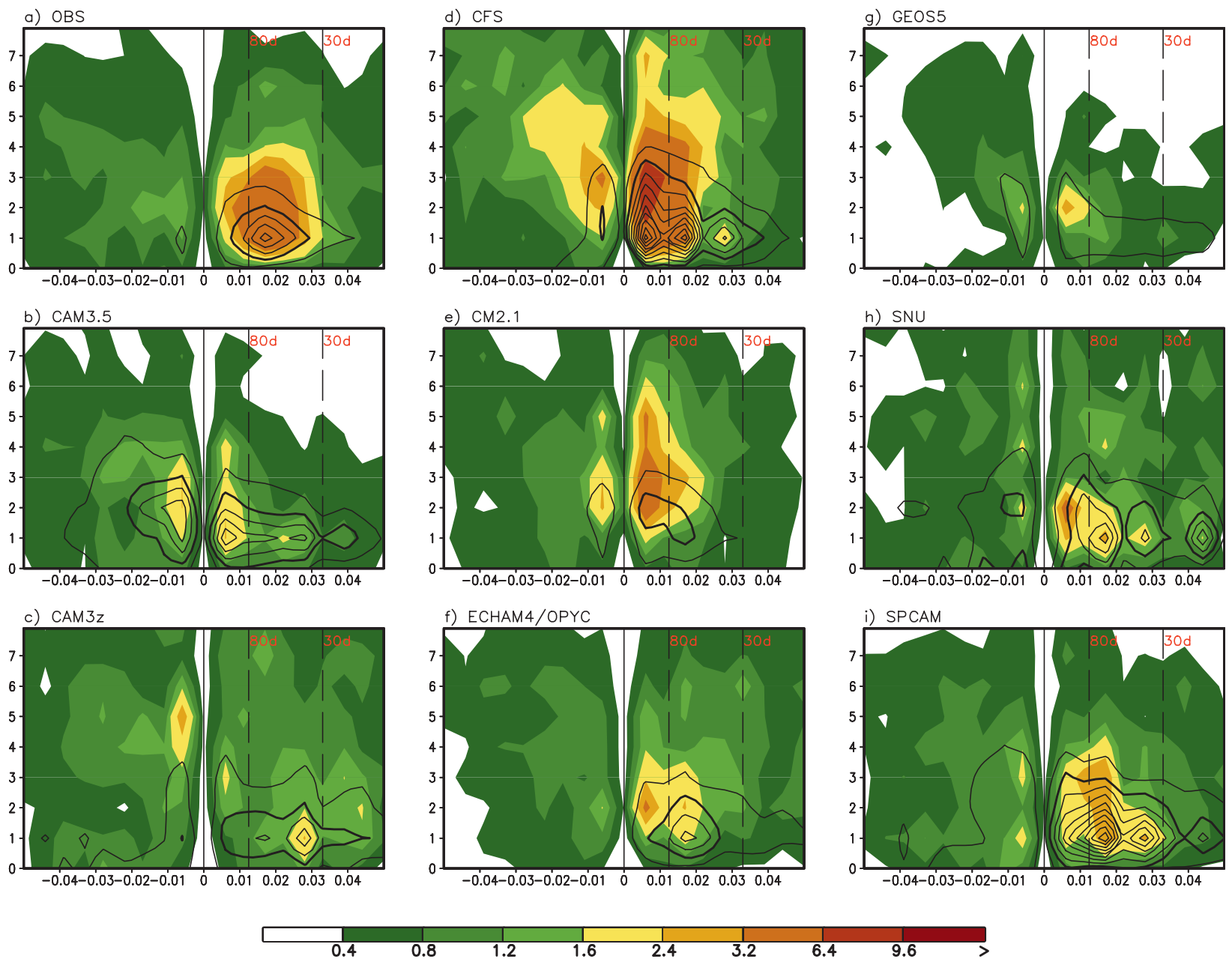

FIG. 4. November-April wavenumber-frequency spectra of $10^{\circ} \mathrm{N}-10^{\circ} \mathrm{S}$ averaged precipitation $\left(\mathrm{mm}^{2}\right.$ day $\left.^{-2}\right)(\mathrm{shaded})$ and $850-\mathrm{hPa}$ zonal wind $\left(\mathrm{m}^{2} \mathrm{~s}^{-2}\right.$ ) (contoured) for the (a) CMAP/NCEP/NCAR, (b) CAM3.5, (c) CAM3z, (d) CFS, (e) CM2.1, (f) ECHAM4/OPYC, (g) GEOS5, (h) SNU, and (i) SPCAM. Individual November-April spectra were calculated for each year and then averaged over all years of data. Only the climatological seasonal cycle and time mean for each November-April segment were removed before calculation of the spectra. The bandwidth is (180 days $)^{-1}$.

An important metric derived from the wavenumberfrequency spectra is the east-west ratio of MJO spectral power shown in Fig. 5. In observations, the east-west power ratio is $\sim 3-4$ for both precipitation and $U_{850}$. For $U_{850}$ three (five) of the models have larger (smaller) ratios compared to observation. Our precipitation power ratios are consistent with Lin et al. (2006), who showed that most of the CMIP3 models have a smaller east/west ratio than observed (their Fig. 10).

\section{MJO modal analysis}

In previous studies, the MJO has been isolated using empirical orthogonal function analysis using different variables such as velocity potential (e.g., Lau and Lau 1986; Knutson and Weickmann 1987), relative vorticity (e.g., Annamalai et al. 1999), winds (e.g., Gutzler and Madden 1989; Maloney and Hartmann 1998; Sperber et al. 2000), and OLR (e.g., Hendon and Glick 1997; Sperber 2003; Sperber et al. 2005). As such, because of the use of different variables for isolating the MJO, direct comparison of MJO quality in models is not possible. We use the CL-MJOWG08 level-2 multivariate combined EOF (CEOF) technique developed by Wheeler and Hendon (2004, hereafter WH04) in which OLR, $U_{850}$, and $U_{200}$ are used to extract the MJO modes. This multivariate approach isolates the convective and baroclinic zonal wind signature of the MJO. The study of WH04 used unfiltered input data to the CEOF analysis to develop a real-time MJO diagnostic for their experimental MJO forecast system, whereas we use 20-100day bandpass filtered data to facilitate isolating the MJO 


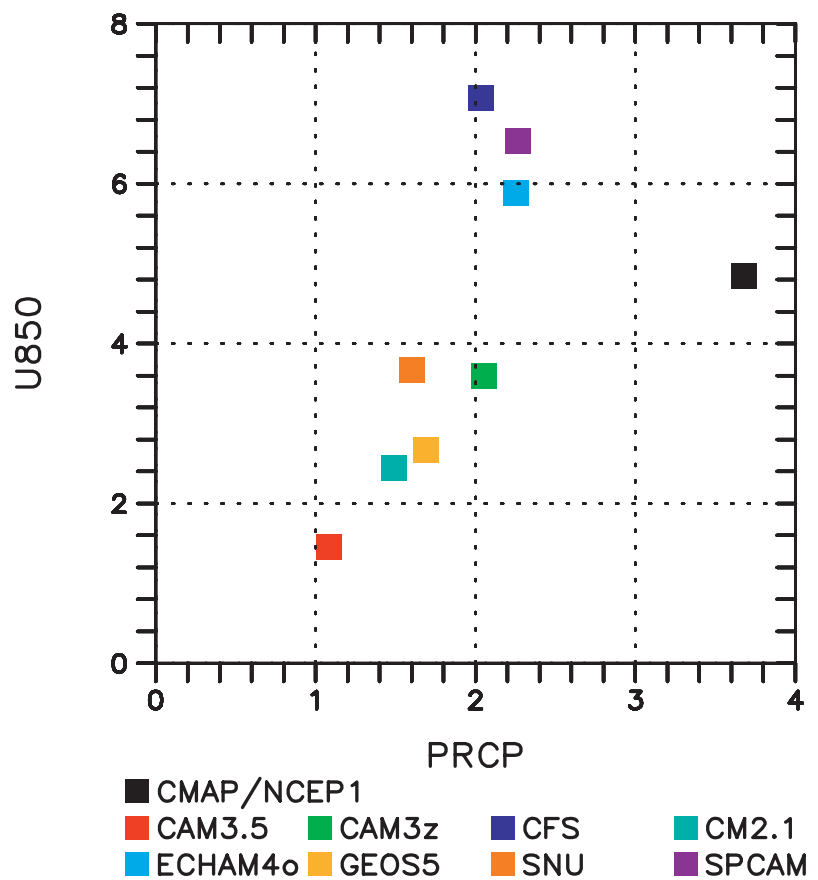

FIG. 5. Scatterplot of east/west ratio of power based on the data in Fig. 4. The east/west ratio is calculated by dividing the sum of eastward propagating power by the westward propagating counterpart within wavenumbers 1-3 (1-2 for zonal wind), period 30-80 days.

modes. We specifically focus on the evaluation of 1) significant separation of the leading CEOFs from the higher modes, 2) the similarity of the model eigenvector pairs with observed patterns, 3 ) determination of the dominant time scale of the MJO PCs, and 4) the mean coherence squared between the leading PCs at the MJO time scale (30-80 days).

\section{a. MJO mode from CEOF analysis}

The first two CEOFs from observations and the models are shown in Fig. 6. In observations, the first mode, seen in the upper panel of Fig. 6a, captures the enhanced convective activity over the eastern Indian Ocean and Maritime Continent, while in the lower panel of Fig. 6a the second mode captures the enhanced convection over the western/central Pacific Ocean and the suppressed convection over the Indian Ocean. Together these two modes constitute the eastward propagating MJO, and explain more than $43 \%$ of the filtered variance. As seen in these figures, the upper (dashed line) and lower (solid line) troposphere zonal winds are out of phase with one another, thus demonstrating the baroclinic structure of the MJO. Additionally, there is a signal displacement of the zonal wind maxima relative to the convection signal with low-level easterlies (westerlies) tending to lead (trail) the convective maximum.
The match between the simulated and observed modes is objectively determined by examining pattern correlations between observed and simulated eigenvectors (Fig. 6). The pattern correlations range from 0.64 (CAM3z, Maritime Continent mode) to $\geq 0.8$ for CAM3.5, CFS, CM2.1, ECHAM4/OPYC, and SPCAM, suggesting good agreement with observations in representing the MJO spatial patterns, especially for the latter models. Except for CM2.1, the two leading modes are statistically distinguishable from the higher-order modes, as in observations, although the percent variance explained by the models is smaller than observed. The phase difference (not shown) between the PCs is nearly $90^{\circ}$, which means the upper panel leads the lower panel by $1 / 4$ cycle for observations and all models. For the models, the baroclinic zonal wind signature is better represented than the convective pattern. For example, the CFS has maximum convective amplitude with CEOF1 in the Western Hemisphere, whereas in observations the maximum amplitude is in the Eastern Hemisphere.

To assess whether the extracted MJO modes are physically meaningful and distinct from a red noise process, we calculate power spectra of unfiltered PCs. The unfiltered PCs are obtained by projecting the leading CEOFs in Fig. 6 onto unfiltered data (with only the seasonal cycle removed). If the power spectra of the unfiltered PCs, shown in Fig. 7, yield a statistically significant peak at MJO time scales, then we have increased confidence that the extracted MJO modes are real. In observations (Fig. 7a), statistically significant spectral power at the $99 \%$ confidence level relative to a red noise process is concentrated at periods of 30 to 80 days. CFS, ECHAM4/OPYC, and SPCAM (Figs. 7d,f,i) best represent the observed time scale, although the power is model dependent. This analysis clearly highlights the benefit in using a multiple diagnostic technique to analyze an MJO simulation. Although the CFS here appears to produce an observed PC spectrum superior to some other models, the diagnosed spatial structure of the leading CEOFs indicates that its MJO has significant biases relative to observations. Of the remaining models, CAM3.5, CAM3z, and SNU (Figs. $7 \mathrm{~b}, \mathrm{c}, \mathrm{h})$ have the largest variance at periods less than 30 days, while CM2.1 (Fig. 7e) is dominated by excessive power at low frequencies.

\section{b. MJO life cycle evolution}

Plotting PC1 versus PC2, we evaluate the phasespace evolution of the MJO life cycle. For each of eight subphases we composite 40-day segments that start from that subphase having an initial MJO amplitude $\left[\left(\mathrm{PC}^{2}+\mathrm{PC}^{2}\right)^{1 / 2}\right]$ larger than 1.5. In observations, Fig. 8a, 

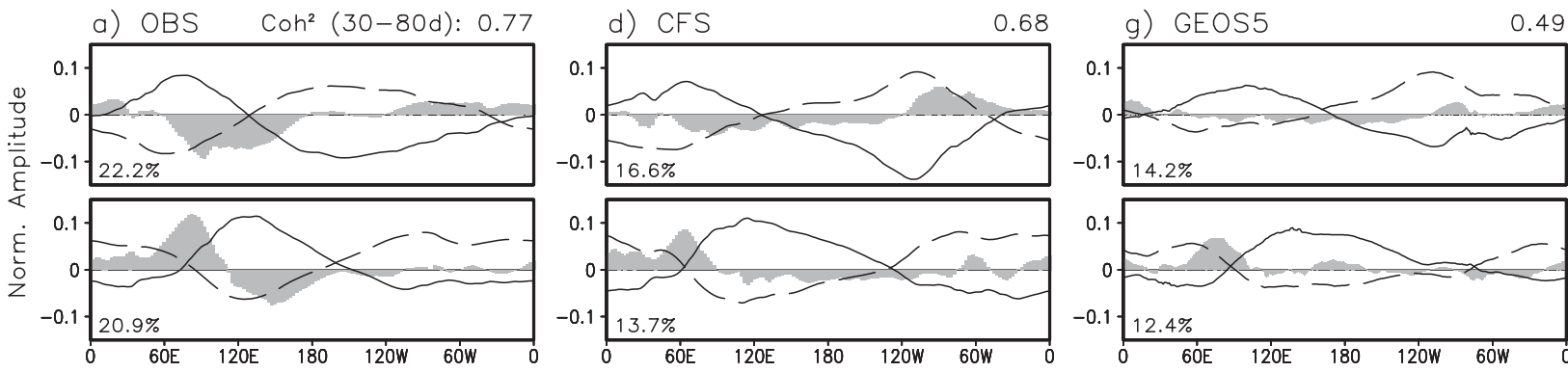

b) $\mathrm{CAM} 3.5$

0.63

e) CM2.1

h) $\mathrm{SNU}$

0.62
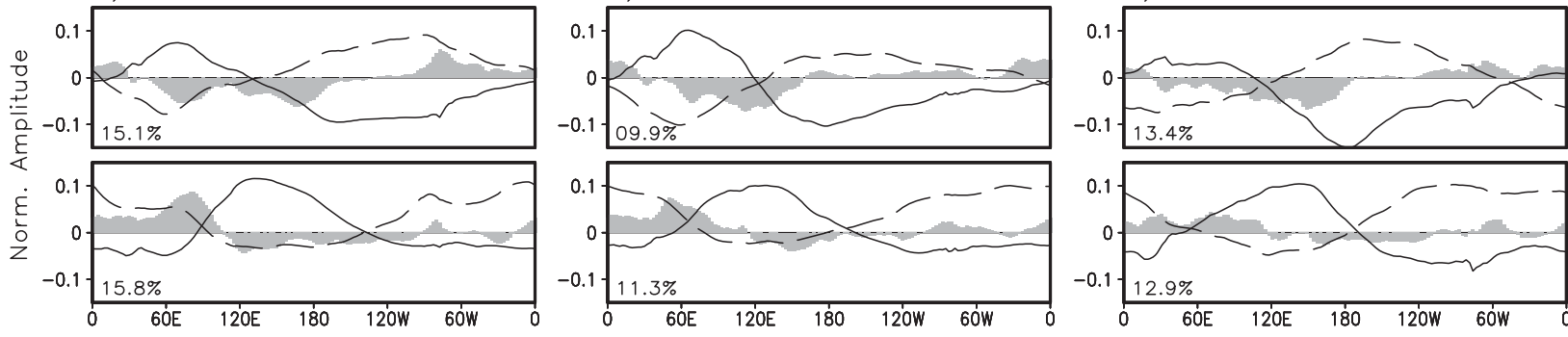

c) $\mathrm{CAM} 3 \mathrm{z}$

0.60
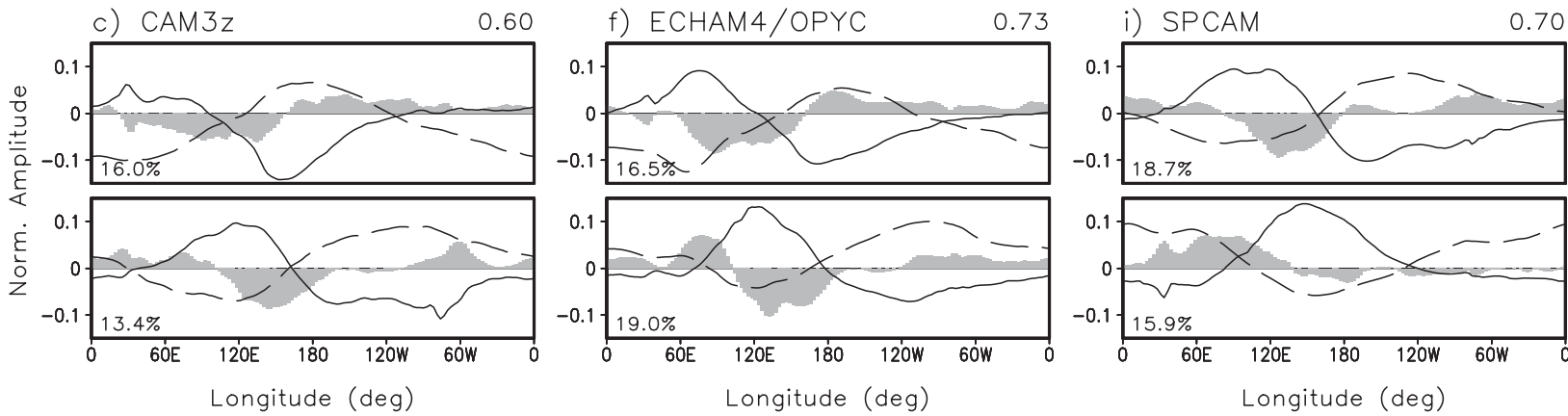

FIG. 6. First two CEOF modes of $20-100$-day $15^{\circ} \mathrm{S}-15^{\circ} \mathrm{N}$ averaged $850-\mathrm{hPa}$ and $200-\mathrm{hPa}$ zonal wind and OLR for the (a) NCEP/NCAR and AVHRR, (b) CAM3.5, (c) CAM3z, (d) CFS, (e) CM2.1, (f) ECHAM4/OPYC, (g) GEOS5, (h) SNU, and (i) SPCAM models. The total variance explained by each mode is shown in the lower left of each panel. The mean coherence squared between principal components of two modes within a 30-80-day period is given above the upper panel. Sign and location (upper or lower) of each mode are arbitrarily adjusted to be similar to observation. The mode having the largest percentage variance explained is the first mode.

the amplitude decays as the MJO life cycle evolves, finally crossing the unit variance circle into the realm that we refer to as a "weak MJO." As shown in Table 2, the average $e$-folding decay time over all initial subphases is $\sim 31$ days for observations, with all models having a faster decay time scale ( $\sim 20-29$ days). The shape of the phase-space spiral depends on two factors: 1) the ability of the model to evolve an MJO and 2) the preferred period of the MJO. For example, CAM3.5 and CM2.1 have nearly identical decay times, but the CM2.1 phase-space plot (Fig. 8e) displays a more open spiral compared to that of CAM3.5 (Fig. 8b). This arises because the preferred MJO time scale in CM2.1 is about 80 days (Fig. 7e), whereas that of CAM3.5 is about 25 days (Fig. 7b). Thus, CM2.1 evolves through fewer MJO life cycle subphases compared to CAM3.5, as the MJO amplitude of both decays on nearly the same time scale.

\section{c. MJO life cycle composite}

MJO life cycle composites are constructed by averaging bandpass filtered anomalies across all days that fall within a given phase when the MJO amplitude is greater or equal to 1 . We evaluate OLR, surface latent heat flux, 925-hPa moisture convergence, and the vertical specific humidity profile at three different longitudes.

Figure 9 shows phase-longitude diagrams of OLR and surface latent heat flux anomalies. Observations show two convective maxima (Fig. 9a), one over the eastern Indian Ocean and the other over the west Pacific Ocean with weakened convection over the Maritime Continent. The strong convective signal is preceded by a negative evaporation anomaly; positive evaporation anomalies follow the enhanced convection. Models generally capture this relationship although the amplitude of the evaporation anomaly associated with convection is especially weak 
a) OBS

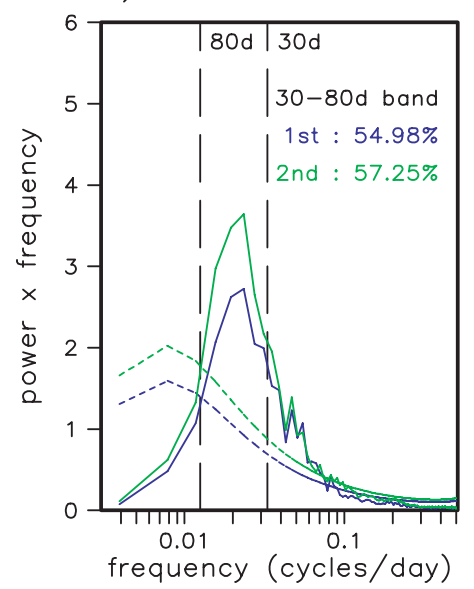

b) $\operatorname{CAM} 3.5$



c) $\mathrm{CAM}_{3 \mathrm{z}}$

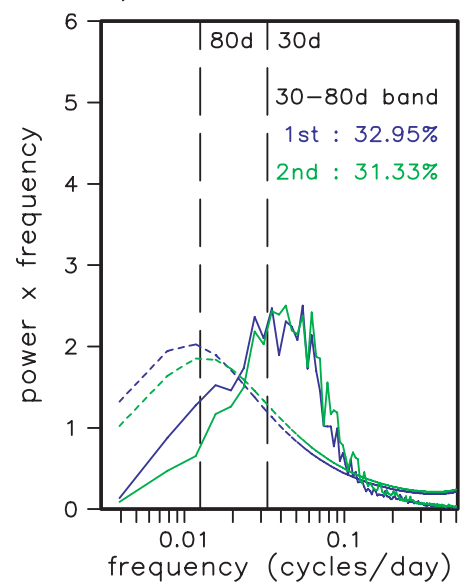

d) CFS

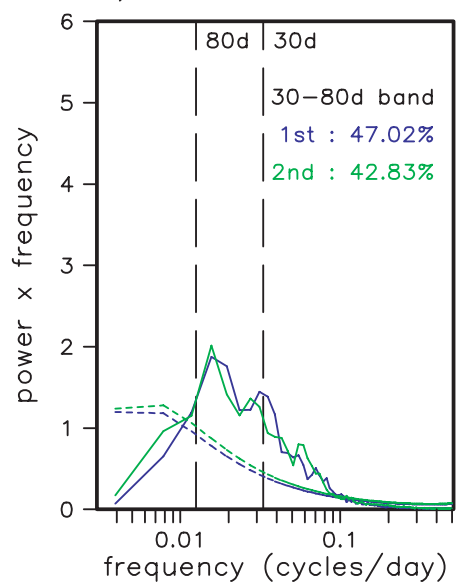

e) $\mathrm{CM} 2.1$

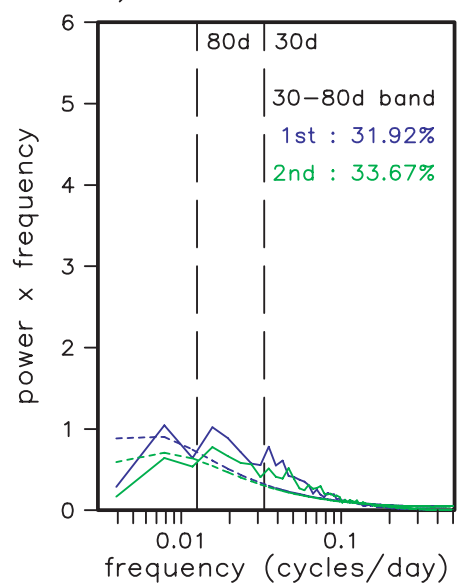

f) ECHAM 4/OPYC

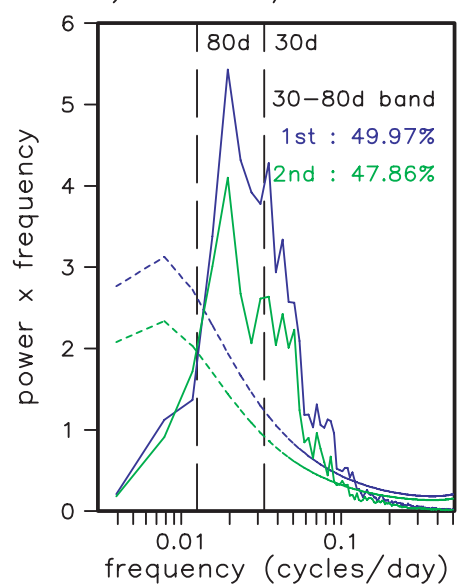

g) GEOS5

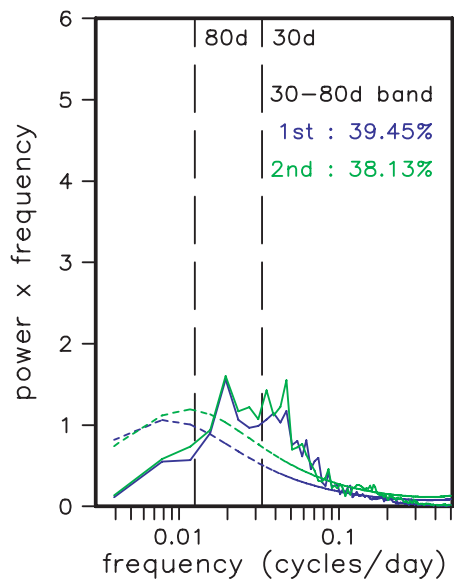

h) SNU

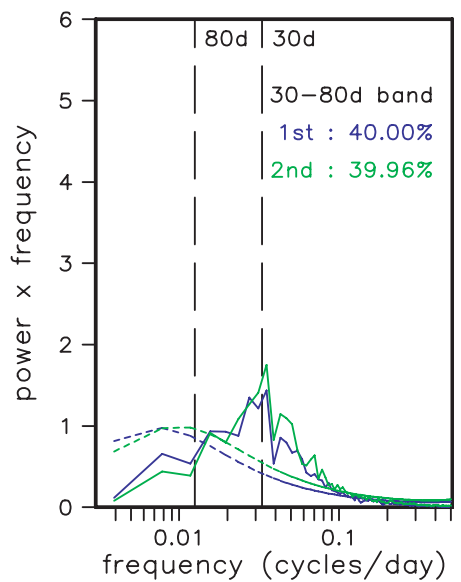

i) SPCAM

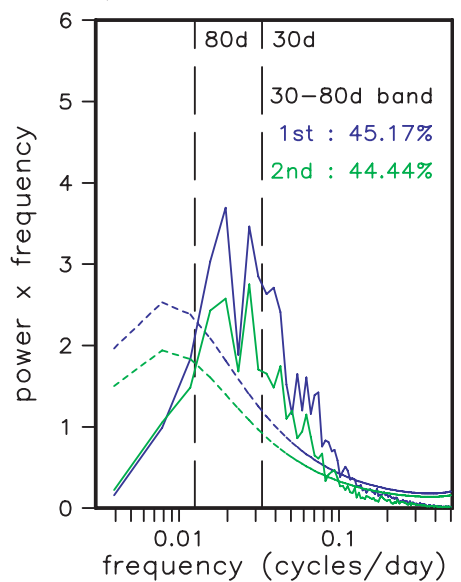

FIG. 7. The power spectrum of the unfiltered PC derived by projecting the CEOFs onto unfiltered data (seasonal cycle removed): first mode (blue) and second mode (green). Dashed lines show the $99 \%$ confidence limit for a red noise spectrum. 
a) OBS

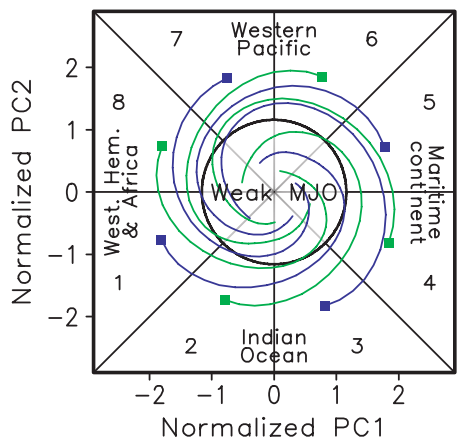

b) $\operatorname{CAM} 3.5$

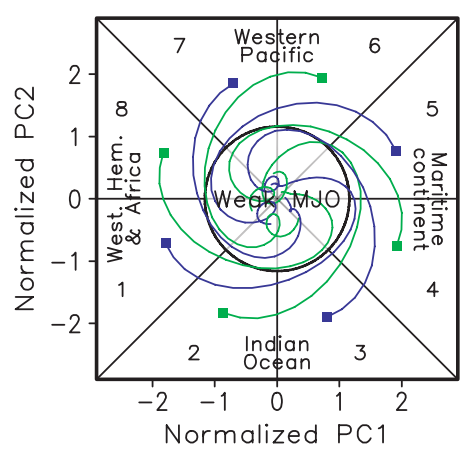

c) $\mathrm{CAM} 3 z$

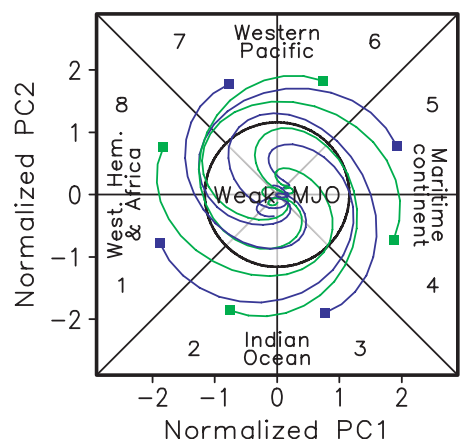

d) CFS

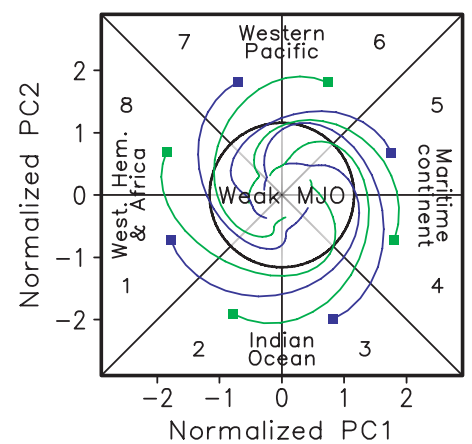

e) $\mathrm{CM} 2.1$

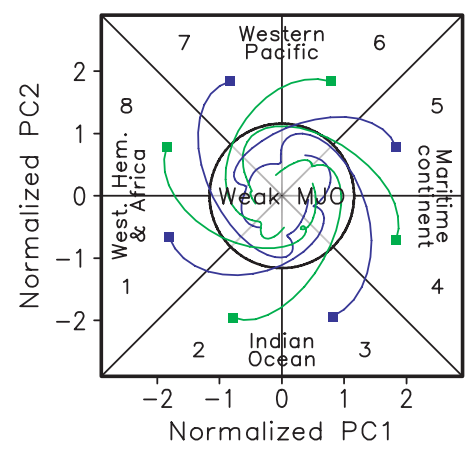

f) ECHAM4/OPYC

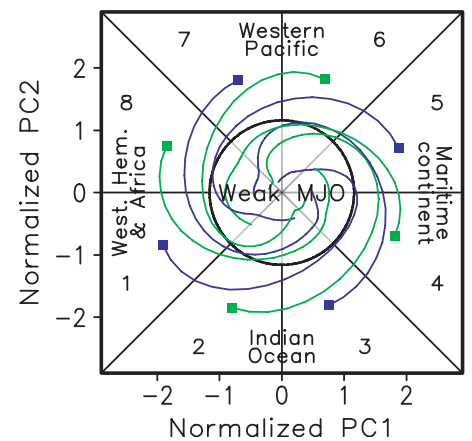

g) GEOS5

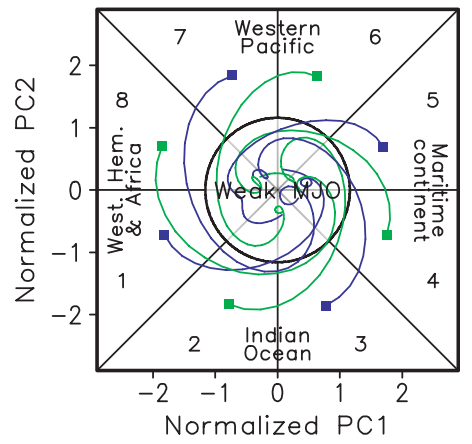

h) SNU

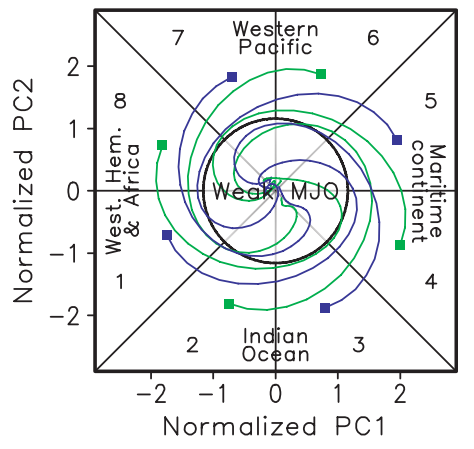

i) SPCAM

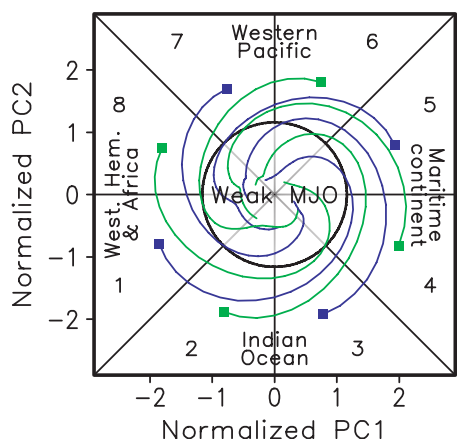

FIG. 8. PC1 and PC2 phase space composite curves of the MJO index from the CEOF analysis [odd number (blue) and even number (green) initial phase]. The PCs have each been normalized by their respective standard deviations. For each initial phase, strong cases are selected when the $\mathrm{MJO}$ amplitude $\left(\mathrm{PC}^{2}+\mathrm{PC}^{2}\right)^{1 / 2}$ exceeded 1.5. Then data for each of the next 40 days from the initial day are averaged over all strong cases to show the evolution of the MJO index.

in CAM3.5 and GEOS5 (Figs. 9b,g) in which the convective anomalies exhibit little or no eastward propagation. Contrary to observations, the CFS model (Fig. 9d) has its largest latent heat flux signal over the eastern Pacific Ocean and largest OLR amplitude in the Atlantic.

Frictional wave conditional instability of the second kind (wave-CISK) has been hypothesized as a mechanism of maintaining the MJO in many theoretical (Wang 1988; Salby et al. 1994), observational (Salby et al. 1994;
Salby and Hendon 1994; Maloney and Hartmann 1998; Sperber 2003), and modeling (Lee et al. 2003; Sperber et al. 2005) studies. This theory requires frictional moisture convergence within the planetary boundary layer east of the deep convection. In Fig. 10, we plot a longitude-phase diagram of OLR and 925-hPa moisture convergence anomalies for observations and models. Owing to quality concerns of the NCEP reanalysis moisture field (Tian et al. 2006), the result from ERA-40 is also plotted (Fig. 10f). Over the Eastern Hemisphere 
TABLE 2. Average of $e$-folding time scale over all initial phases.

\begin{tabular}{lc}
\hline \multicolumn{1}{c}{ Model } & $e$-folding day \\
\hline Observation & 31.2 \\
CAM3.5 & 20.5 \\
CAM3z & 21.5 \\
CFS & 24.9 \\
CM2.1 & 20.7 \\
ECHAM4/OPYC & 28.9 \\
GEOS & 20.7 \\
SNU & 22.8 \\
SPCAM & 24.5 \\
Model average & 23.0 \\
\hline
\end{tabular}

the MJO 925-hPa moisture convergence anomalies from NCEP are weaker than those from ERA-40, with NCEP anomalies extending farther east into the central and eastern Pacific (Figs. 10a,f). All simulations show low-level moisture convergence leading the enhanced MJO convection. CAM3.5, CAM3z, SNU, and SPCAM (Figs. 10b,c,i,j) exhibit the extension of the moisture convergence anomalies into the central and eastern Pacific, akin to NCEP-NCAR reanalysis. Conversely, CFS, CM2.1, and ECHAM4/OPYC (Figs. 10d,e,g), are most similar to ERA-40, with the moisture convergence signal mostly confined to the warm pool region $\left(40^{\circ}-160^{\circ} \mathrm{E}\right)$.

The equatorial vertical structure of the MJO has been examined in a number of studies (Rui and Wang 1990; Myers and Waliser 2003; Sperber 2003; Kiladis et al. 2005; Tian et al. 2006). Figure 11 presents MJO life cycle composites of the vertical structure of specific humidity at three different longitudes: (left) the Indian Ocean $\left(80^{\circ} \mathrm{E}\right)$ and the (middle) west $\left(130^{\circ} \mathrm{E}\right)$ and (right) east Pacific Ocean $\left(140^{\circ} \mathrm{W}\right)$. Note that horizontal axis (time) is reversed for easier comparison of our composites with usual east-west oriented zonal cross sections. In both reanalyses, Figs. 11a and 11f, the low-level moistening precedes enhanced convection over the warm pool longitudes $\left(80^{\circ}\right.$ and $\left.130^{\circ} \mathrm{E}\right)$. The slope of the vertical tilt depends on the longitude, consistent with the findings of Sperber (2003) and Kiladis et al. (2005). In the warm pool longitudes, the peak level for the specific humidity anomaly occurs at $\sim 600 \mathrm{hPa}$ where the convection is strongest. ERA-40 (Fig. 11f) shows one more peak leading the convective anomaly near the 800 -hPa level in the Indian Ocean, which is not represented in NCEP and all participating models. It is-although interesting-not clear in this stage whether the lower peak in ERA-40 corresponds to some physical mechanisms (e.g., moistening by shallow convections) or not. As in observations, the vertical structure of moisture associated with the MJO depends on the geographical location in all models. However, the models do exhibit some significant dif- ferences from observations. For example, in CAM3.5 the mid- to upper-tropospheric moisture anomalies are apparent, but only a weak signal exists in the lower troposphere, especially in the warm pool region (Figs. 11a,b). CFS, ECHAM4/OPYC, and SPCAM give the most realistic simulations of moisture anomalies associated with the MJO (Figs. 11d,g,j).

\section{Discussion}

The MJOWG diagnostics presented in sections 3 and 4 assess the ability of the models to represent the MJO. While these diagnostics point to shortcomings in the ability of models to simulate the MJO, they do not directly indicate which physical processes are most important and/or responsible for the quality of the MJO. This issue was a topic of considerable discussion at a recent CLIVAR-sponsored MJO workshop (Sperber and Waliser 2008) with the recommendation that, in addition to the diagnostics established to date, more process-oriented diagnostics should be explored and developed in the future. In this section, we make an initial attempt toward this objective.

If we consider the coherence-squared $\mathrm{PC} 1$ versus $\mathrm{PC} 2$ in the intraseasonal band as a metric of MJO simulation skill, Fig. 6, [see Hendon and Wheeler (2008) for the details of the calculation], we can relate it to basic aspects of model performance, in this case the quality of the timemean state of key variables, Fig. 12. Only for precipitation is there a $5 \%$ significant direct relationship between MJO skill and the time-mean state. This suggests two possibilities: 1) one must have a good mean state background of precipitation to have the potential to represent the MJO or 2) representing a reasonable spectrum of precipitation variability (including the MJO) is the proper way to attain a realistic mean state (e.g., Waliser et al. 2003). Irrespective of which possibility is correct, further investigation of precipitation and moist processes is warranted since these may have a bearing on the ability to represent the MJO.

To gain some insight into precipitation and moist processes, in Fig. 13 we plot the vertical profile of relative humidity versus precipitation intensity (owing to the lack of data availability, results from all models are not presented). This diagnostic has previously proven useful for gaining insight into the superior ability of SPCAM to simulate the MJO relative to CAM3.0 (Thayer-Calder 2008; Thayer-Calder and Randall 2009). In the observations (GPCP precipitation and ERA-40 RH, Fig. 13a), $\mathrm{RH}$ in the troposphere gradually increases with increasing precipitation and becomes nearly constant throughout the troposphere when the rainfall amount is larger than about $70 \mathrm{~mm}$ day $^{-1}$. This implies that heavy rainfall is inhibited 



FIG. 9. Phase-longitude diagram of OLR [contour plotted every $5 \mathrm{~W} \mathrm{~m}^{-2}$, positive (green) and negative (purple)] and surface latent heat flux $\left(\mathrm{W} \mathrm{m}^{-2}\right.$, shaded). Phases are from MJO life cycle composite and values averaged between $5^{\circ} \mathrm{S}$ and $5^{\circ} \mathrm{N}$. 

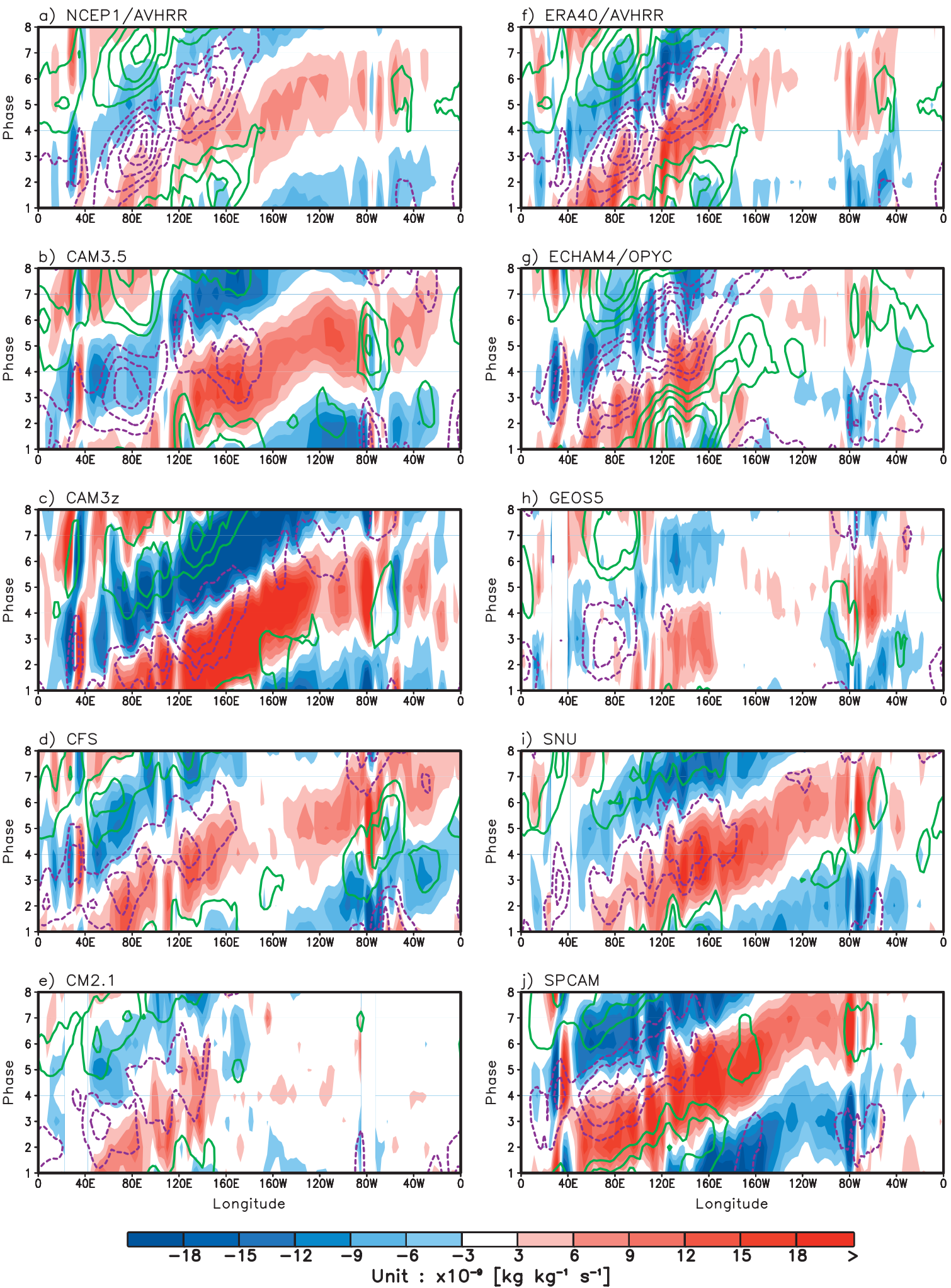

FIG. 10. As in Fig. 9 but for 925-hPa moisture convergence $\left(\mathrm{kg} \mathrm{kg}^{-1} \mathrm{~s}^{-1}\right)$. 

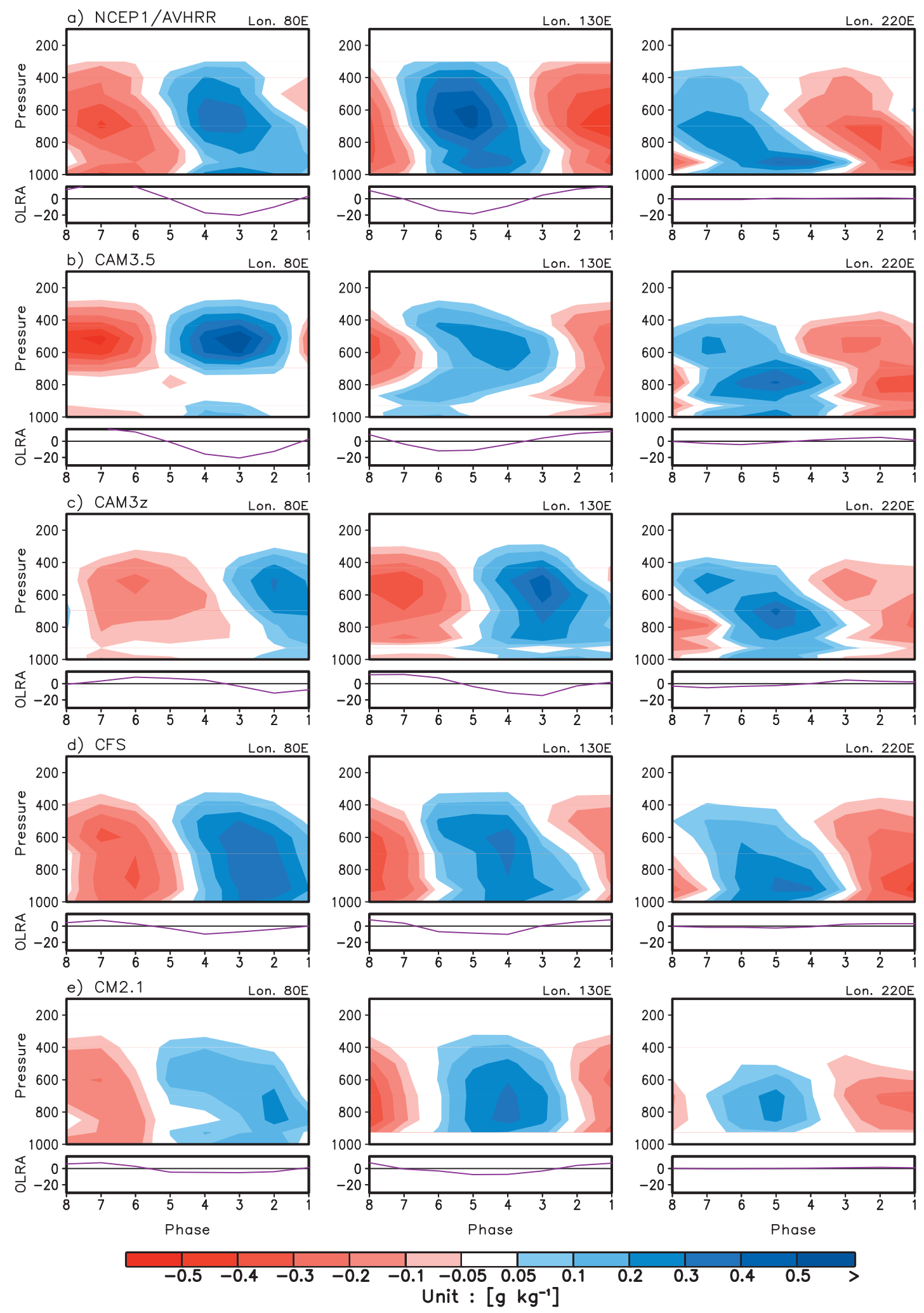

FIG. 11. Pressure-phase diagram of specific humidity anomalies $\left(\mathrm{g} \mathrm{kg}^{-1}\right)$ (shaded) at three different longitudes: (left) $80^{\circ} \mathrm{E}$, (middle) $130^{\circ} \mathrm{E}$, (right) $140^{\circ} \mathrm{W}$ averaged between $5^{\circ} \mathrm{S}$ and $5^{\circ} \mathrm{N}$. Phases are defined as in Fig. 10 . OLR anomalies $\left(\mathrm{W} \mathrm{m}^{-2}\right.$ ) are plotted in lower panel. The horizontal axis (phase) is reversed for easier comparison of our composites with usual east-west oriented zonal cross sections. 

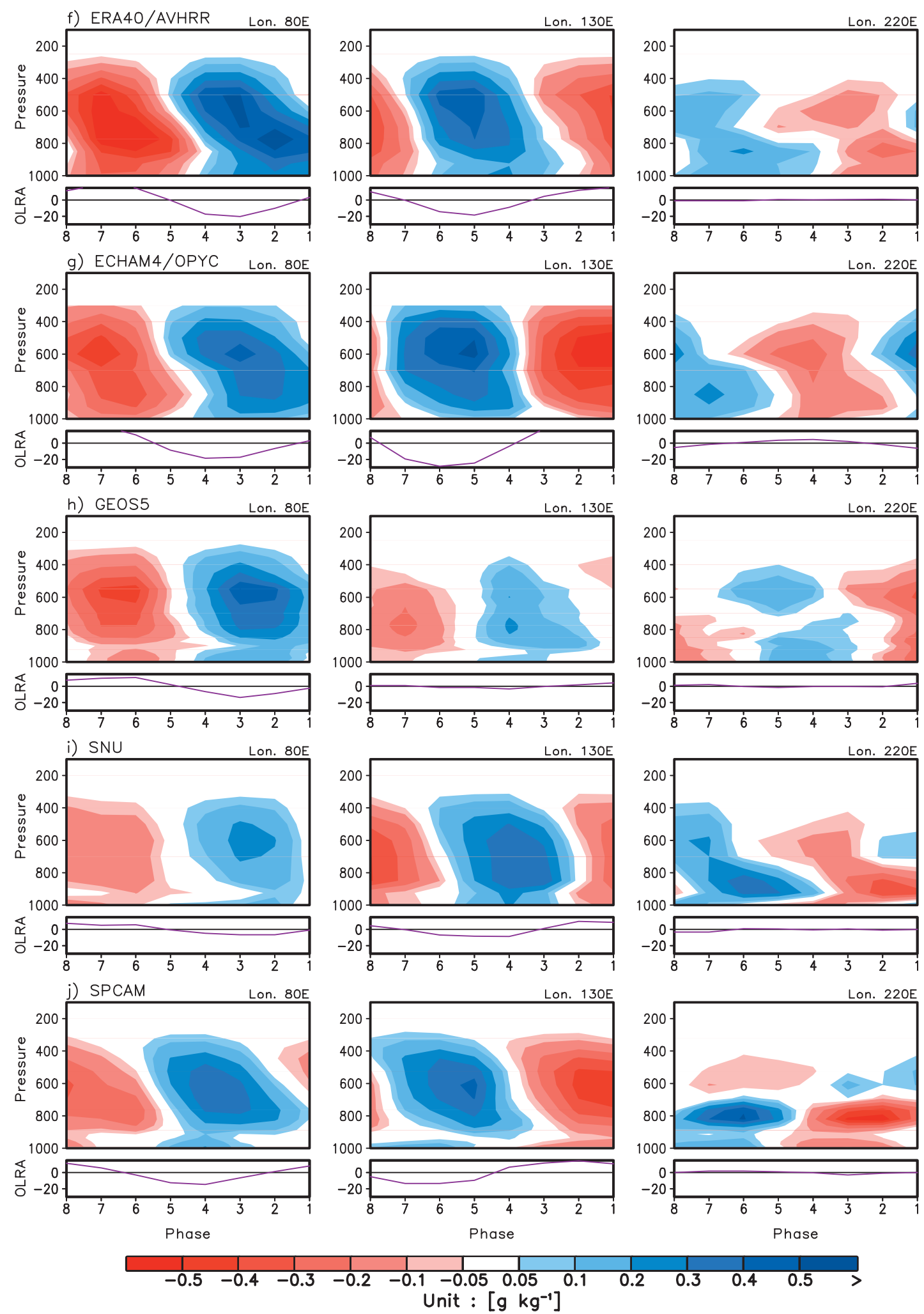

FIG. 11. (Continued) 
(a) PRCP (0.73)

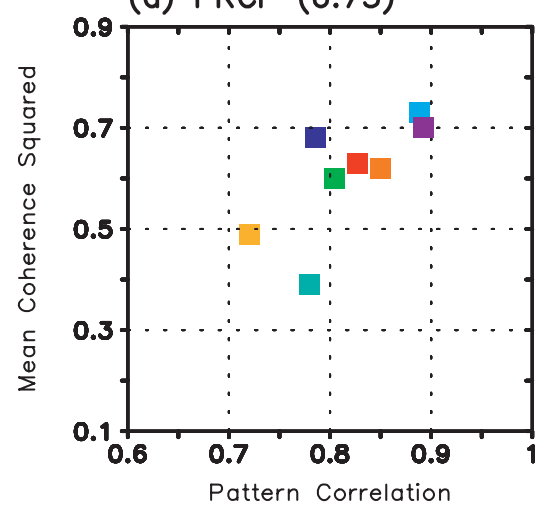

(c) U850 (0.24)

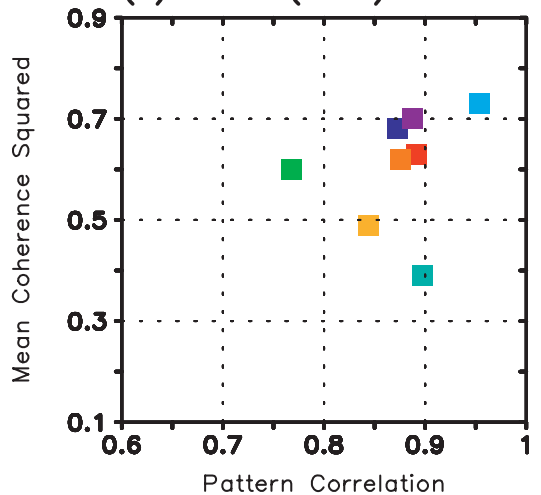

CAM3.5 CAM3z ECHAM4O GEOS5
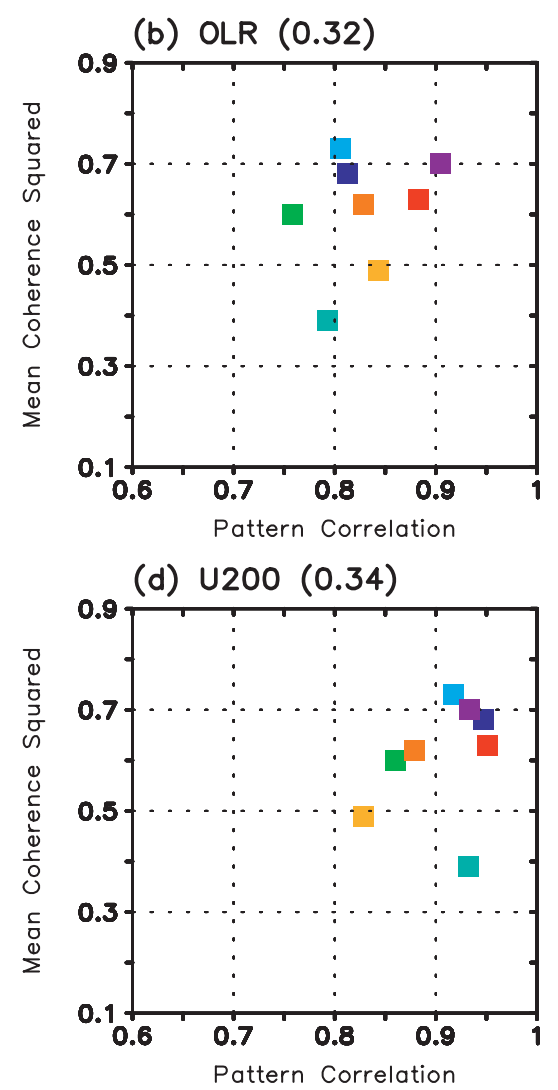

CFS

CM2.1

FIG. 12. Scatterplot of mean coherence-squared PCs vs the pattern correlation of NovemberApril time mean (a) precipitation, (b) 850-hPa zonal wind, (c) OLR, and (d) 200-hPa zonal wind. The region for the pattern correlation calculation is $25^{\circ} \mathrm{S}-15^{\circ} \mathrm{N}, 0^{\circ}-360^{\circ} \mathrm{E}$. Mean coherence squared is calculated between two leading PCs from CEOF analysis (30-80-day period). The value in the parentheses is the correlation between the two variables.

until the column is sufficiently moistened. In the models the column is too dry when precipitation is weak. In observations RH of $95 \%$ is rarely obtained (Fig. 13a), whereas the models produce excessive RH near the tropopause when the precipitation rate is larger. This error extends to the middle-lower troposphere in all models except ECHAM4/OPYC (Fig. 13e). Since this model also has one of the better representations of the MJO, our result lends support to tropospheric moisture control on precipitation events as an important process in simulating the MJO. Thayer-Calder and Randall (2009) show a similar composite plot of SPCAM, which is similar to observations.

To correctly represent the life cycle of precipitation processes, another important consideration is the adequate representation of stratiform rainfall. Using recently released precipitation and latent heat estimates from TRMM, Morita et al. (2006) and Benedict and
Randall (2007) showed that shallow and congestus cumulus prevail in the early stages of MJO related convective activity, while deep cumulonimbus and stratiform clouds dominate during the peak and decaying stages. Lin et al. (2004) showed the important role of stratiform rainfall in producing a top-heavy vertical heating structure associated with the observed MJO, and Dai (2006) showed that many GCMs suffer from a lack of stratiform rainfall compared to observation. In observations about $40 \%$ of total precipitation in the tropics is in the form of stratiform rainfall (Schumacher and Houze 2003). The annual-mean stratiform rainfall fraction, presented in Fig. 14a based on the TRMM $3 \mathrm{~A} 25$ product, has a lower stratiform rain fraction compared to the analysis of Schumacher and Houze (2003), who used the TRMM 2A23 product. Nevertheless, CAM3.5 and CAM3z (Figs. 14b,c) still have a smaller fraction of stratiform rainfall (i.e., that due to large-scale 

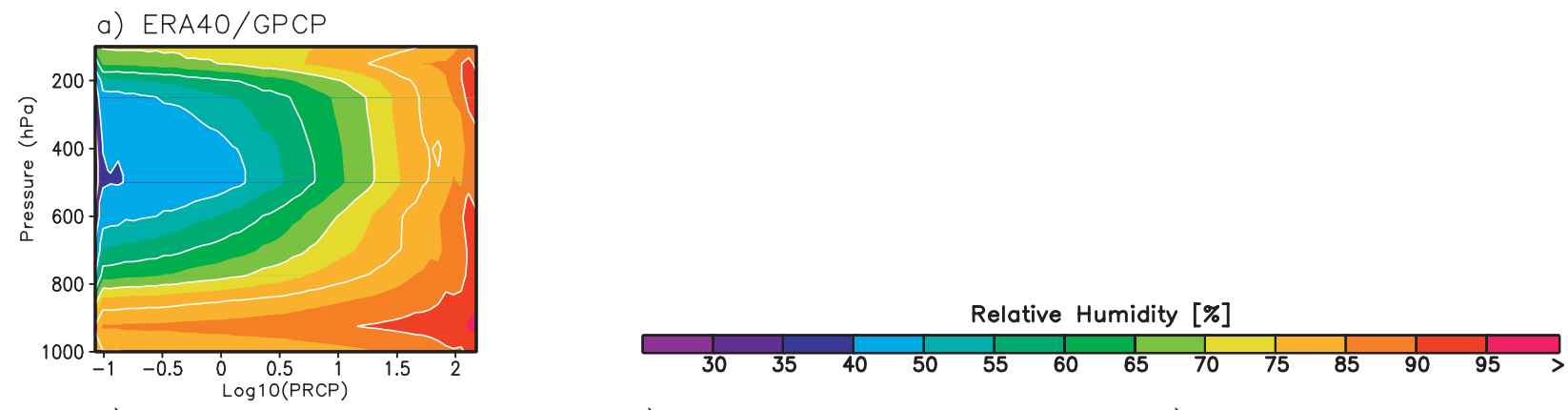

b) $\mathrm{CAM} 3.5$

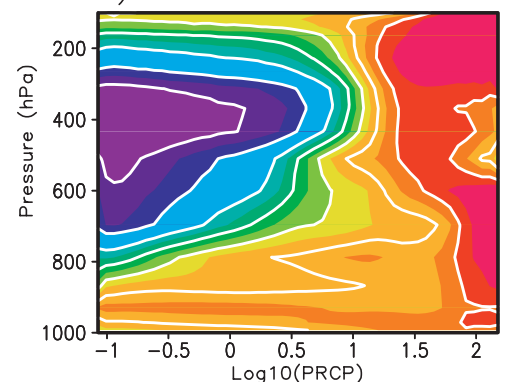

d) $\mathrm{CM} 2.1$

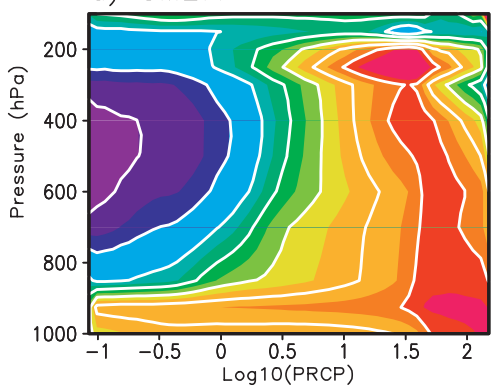

e) ECHAM 4/OPYC

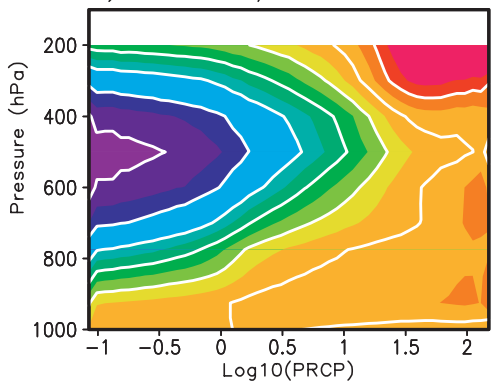

f) SNU

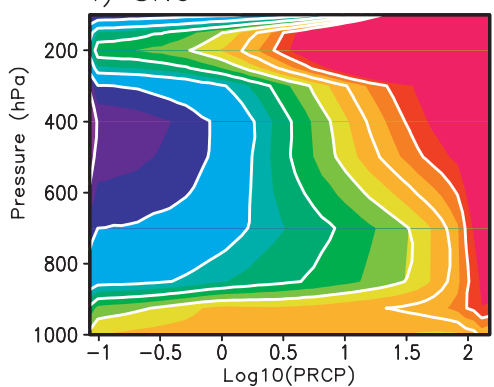

g) $\mathrm{SNU}$ (no_trigger)

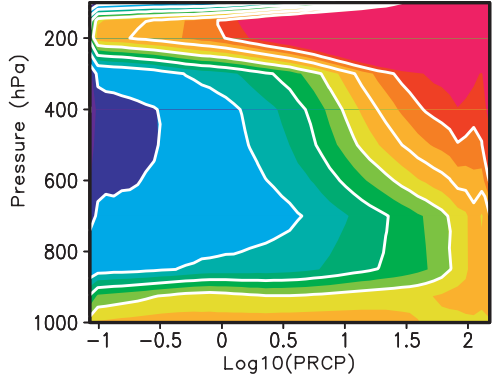

FIG. 13. Composite vertical profile of relative humidity based on precipitation rate: (a) ERA-40/GPCP, (b) CAM3.5, (c) CAM3z, (d) CM2.1, (e) ECHAM4/OPYC, (f) SNU, and (g) SNU without convective inhibition function. The precipitation rate is plotted on a $\log$ scale with the relative humidity averaged for each bin shown on the $x$ axis. The data is analyzed over $10^{\circ} \mathrm{S}-10^{\circ} \mathrm{N}, 40^{\circ}-220^{\circ} \mathrm{E}$.

condensation) compared to the TRMM 3A25 product. ECHAM4/OPYC (Fig. 14d) is most similar to observations in terms of pattern and fraction over the nearequatorial Indian Ocean and western Pacific, key areas of MJO convective propagation, but elsewhere the fraction is overestimated. SNU also produces similar stratiform rain fractions compared to observations. However, when its trigger function is turned off, SNU has a reduced stratiform rainfall ratio (Fig. 14f) and the troposphere is too dry (Fig. 13g). The intraseasonal variability and the MJO are better simulated by the SNU model with the convective trigger implemented (Lin et al. 2008).

For the ECHAM4/OPYC model, the results in Figs. 13 and 14 indicate that a model with a good MJO also exhibits a realistic representation of precipitation rate versus relative humidity and the partitioning of stratiform versus convective rainfall. The other models, which have poorer MJOs, exhibit less consistency in their ability to represent these experimental diagnostics. Regarding the MJO, these may not be cause and effect relationships, but such a multivariate validation approach is at least useful to suggest where inconsistencies arise with respect to the model physics and observations.

\section{Summary and conclusions}

Standardized MJO diagnostics, developed by the CLIVAR MJOWG (CL-MJOWG08; see http://climate. snu.ac.kr/mjo_diagnostics/index.htm), have been applied to eight climate model simulations. Mean state, variance maps, and wavenumber-frequency diagrams are used to evaluate each model's intraseasonal variability of $U_{850}$ and precipitation, as well as their relationship to the model climatology. Generally, the MJO signal in the large-scale circulation $\left(U_{850}\right)$ is better represented than in 

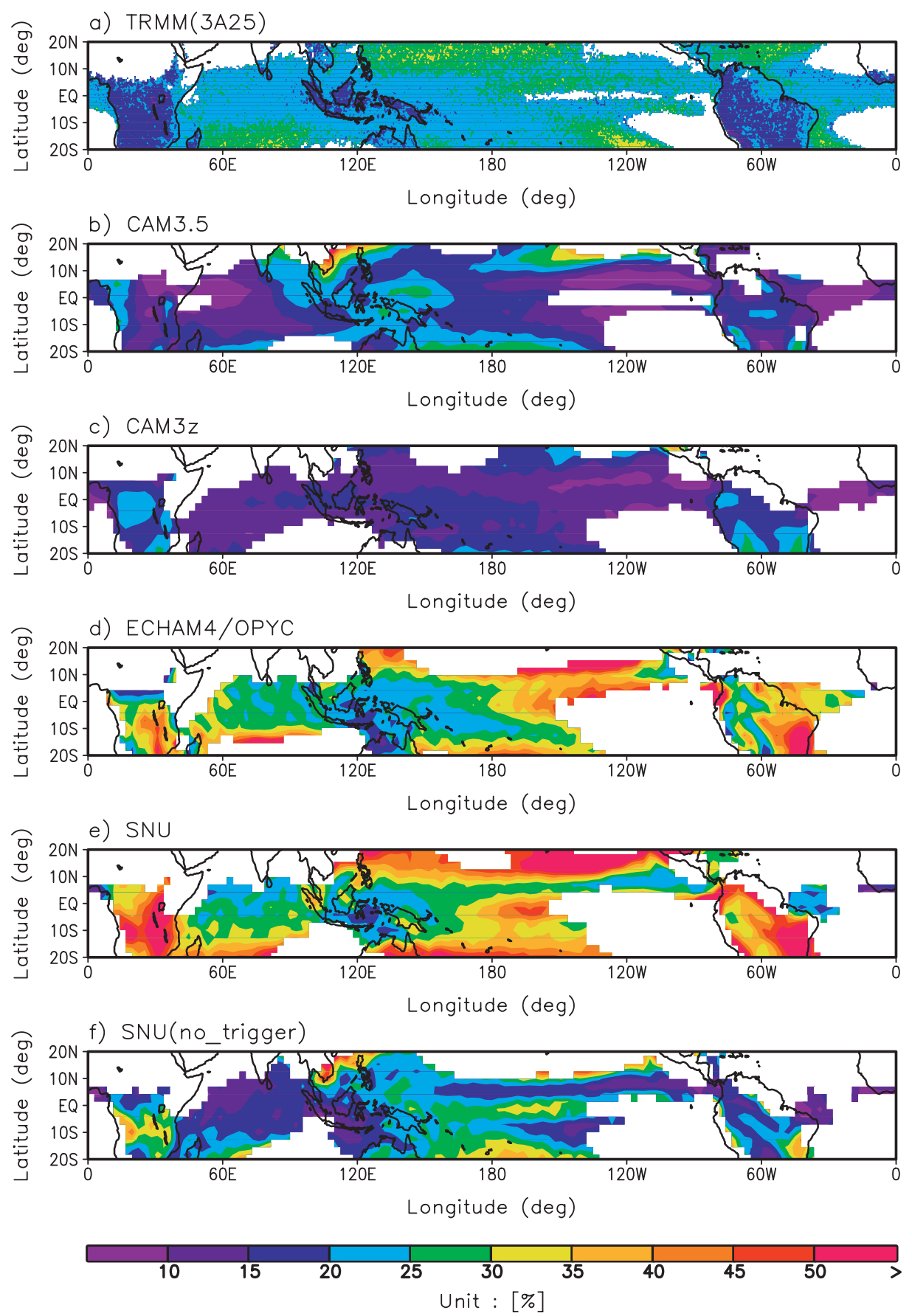

FIG. 14. November-April mean stratiform rain fraction for the (a) TRMM 3A25 product, (b) CAM3.5, (c) CAM3z, (d) ECHAM4/OPYC, (e) SNU and (f) SNU (no trigger). Areas with November-April mean rain of less than $2 \mathrm{~mm}$ day $^{-1}$ are not included.

convection (precipitation). The intraseasonal variability of precipitation and $U_{850}$ is stronger than observed in the majority of GCMs (Fig. 3). Each model's MJO is extracted using 200- and 850-hPa zonal wind and OLR in the combined EOF method of WH04. All models produce a leading pair of CEOFs that represent eastwardpropagating zonal wind variability resembling observations, although OLR structures associated with these CEOFs differ significantly from observations in some models. The leading CEOFs uniformly explain less of 
the variance in the models than observations. Often, the dominant time scale of the model MJO modes is outside of the 30-80-day band. The persistence of strong MJO events is shorter in models than observations. Consistent with the observations as analyzed by $\mathrm{WH} 04$, the multivariate $\mathrm{CEOF}$ method is better than univariate EOF analysis in capturing MJO-like phenomena in climate simulations based on using the coherence-squared PC1 versus $\mathrm{PC} 2$ in the intraseasonal band as a metric of MJO performance (not shown).

Based on community recommendations at a recent MJO workshop (Sperber and Waliser 2008), a number of additional process-oriented diagnostics are considered. Negative surface latent heat flux anomalies to the east of the convective anomalies are seen in most of the models with strong MJO signals. Positive moisture convergence anomalies within the PBL $(925 \mathrm{hPa})$ preceding enhanced convection appear in most of the simulations, supporting the frictional wave-CISK mechanism (Wang 1988; Salby et al. 1994). However, most of the GCMs show errors in the vertical structure of moisture anomalies as a function of MJO phase. Many models do not show the low-level preconditioning of the troposphere that precedes observed convective events. This inability of model moist physics to correctly represent the sensitivity of precipitation to the vertical structure of tropospheric relative humidity cites the need for improved convective parameterizations. Finally, another diagnostic measure of a GCM's treatment of convection, the ratio of stratiform rainfall to total precipitation, is quite varied among the models used here and their similarity to observations is typically poor.

SPCAM and ECHAM4/OPYC show relatively better skill in representing the MJO than the other models. The results indicate that a good MJO simulation is possible through the use of conventional parameterization and by explicitly resolving clouds at each grid point (cf. Miura et al. 2008; Sperber et al. 2008). ECHAM4/OPYC has a quite good mean state of precipitation and low-level wind, noting that annual mean flux adjustment of heat and freshwater were applied to the simulation, which may contribute to the realistic intraseasonal variability in this model (Sperber et al. 2005). Interestingly, diabatic heating (rainfall) is a more difficult variable to simulate than the large-scale circulation field $\left(U_{850}\right)$. Because these variables are closely linked, comparable skill would have been expected. To resolve this paradox and to gain further insight into the process/interactions that are required to enable simulation of the $\mathrm{MJO}$, it will be necessary to archive vertical profiles of the diabatic heating components at a frequent enough sampling (or averaging) rate (e.g., at least 1 day $^{-1}$ ) to gain new insight into the convective interactions necessary for MJO sim- ulation. The approach calls for the use of a hierarchy of models (parameterized through cloud-resolving models) along with suitable observations so that improved parameterizations of convective processes in climate models can be realized. A more realistic representation of the spectrum of variability in climate models will provide a better estimate of how climate extremes will change due to anthropogenic climate change.

Acknowledgments. The MJOWG wishes to acknowledge and thank U.S. CLIVAR and International CLIVAR for supporting this working group and its activities. We would like to specifically acknowledge the administrative support on behalf of the MJOWG by Cathy Stevens of the U.S. CLIVAR Office. D. Kim and I.-S. Kang have been supported by the Korea Meteorological Administration Research and Development Program under Grant CATER_2006-4206 and the BK21 program. K. Sperber was supported under the auspices of the U.S. Department of Energy Office of Science, Climate Change Prediction Program by Lawrence Livermore National Laboratory under Contract DE-AC5207NA27344. D. Waliser's contributions to this study were carried out on behalf of the Jet Propulsion Laboratory, California Institute of Technology, under a contract with the National Aeronautics and Space Administration (NASA). E. Maloney was supported by the Climate and Large-Scale Dynamics program of the NSF under Grant ATM-0832868, and under Award NA050AR4310006 from the National Oceanic and Atmospheric Administration. We thank Dr. M. Wheeler (Centre for Australian Weather and Climate Research) and Prof. B. Wang (University of Hawaii) for helpful comments.

\section{REFERENCES}

Annamalai, H., J. M. Slingo, K. R. Sperber, and K. Hodges, 1999: The mean evolution and variability of the Asian summer monsoon: Comparison of ECMWF and NCEP/NCAR reanalyses. Mon. Wea. Rev., 127, 1157-1186.

Arakawa, A., and W. H. Schubert, 1974: Interaction of a cumulus cloud ensemble with the large-scale environment, Part I. J. Atmos. Sci., 31, 674-701.

Benedict, J. J., and D. A. Randall, 2007: Observed characteristics of the MJO relative to maximum rainfall. J. Atmos. Sci., 64, 2332-2354.

Bergman, J. W., H. H. Hendon, and K. M. Weickmann, 2001: Intraseasonal air-sea interactions at the onset of El Niño. J. Climate, 14, 1702-1719.

Bessafi, M., and M. C. Wheeler, 2006: Modulation of South Indian Ocean tropical cyclones by the Madden-Julian oscillation and convectively coupled equatorial waves. Mon. Wea. Rev., 134, 638-656.

CLIVAR Madden-Julian Oscillation Working Group, 2009: MJO simulation diagnostics. J. Climate, 22, 3006-3030. 
Dai, A., 2006: Precipitation characteristics in eighteen coupled climate models. J. Climate, 19, 4605-4630.

Delworth, T. L., and Coauthors, 2006: GFDL's CM2 global coupled climate models. Part 1: Formulation and simulation characteristics. J. Climate, 19, 643-674.

Fu, X., and B. Wang, 2004: Differences of boreal-summer intraseasonal oscillations simulated in an atmosphere-ocean coupled model and an atmosphere-only model. J. Climate, 17, 1263-1271.

Gutzler, D. S., and R. A. Madden, 1989: Seasonal variations in the spatial structure of intraseasonal tropical wind fluctuations. J. Atmos. Sci., 46, 641-660.

Hayashi, Y., 1979: A generalized method of resolving transient disturbances into standing and traveling waves by space-time spectral analysis. J. Atmos. Sci., 36, 1017-1029.

Hendon, H. H., 2000: Impact of air-sea coupling on the MaddenJulian oscillation in a general circulation model. J. Atmos. Sci., 57, 3939-3952.

— , and J. Glick, 1997: Intraseasonal air-sea interaction in the tropical Indian and Pacific Oceans. J. Climate, 10, 647-661.

—_, and M. C. Wheeler, 2008: Some space-time spectral analyses of tropical convection and planetary-scale waves. J. Atmos. Sci., 65, 2936-2948.

Hong, S.-Y., and H.-L. Pan, 1998: Convective trigger function for a mass-flux cumulus parameterization scheme. Mon. Wea. Rev., 126, 2599-2620.

Huffman, G. J., R. F. Adler, M. M. Morrissey, D. T. Bolvin, S. Curtis, R. Joyce, B. McGavock, and J. Susskind, 2001: Global precipitation at one-degree daily resolution from multisatellite observations. J. Hydrometeor., 2, 36-50.

Inness, P. M., and J. M. Slingo, 2003: Simulation of the MaddenJulian oscillation in a coupled general circulation model. Part I: Comparison with observations and an atmosphere-only GCM. J. Climate, 16, 345-364

,-- , S. J. Woolnough, R. B. Neale, and V. D. Pope, 2001: Organization of tropical convection in a GCM with varying vertical resolution; implications for the simulation of the Madden-Julian oscillation. Climate Dyn., 17, 777-793.

,-- E. Guilyardi, and J. Cole, 2003: Simulation of the Madden-Julian oscillation in a coupled general circulation model. Part II: The role of the basic state. J. Climate, 16, 365-382.

Jia, X., C. Li, J. Ling, and C. Zhang, 2008: Impacts of a GCM's resolution on MJO simulation. Adv. Atmos. Sci., 25, 139-156.

Jiang, X., D. E. Waliser, M. C. Wheeler, C. Jones, M.-I. Lee, and S. D. Schubert, 2008: Assessing the skill of an all-season statistical forecast model for the Madden-Julian oscillation. Mon. Wea. Rev., 136, 1940-1956.

Johnson, R. H., T. M. Rickenbach, S. A. Rutledge, P. E. Ciesielski, and W. H. Schubert, 1999: Trimodal characteristics of tropical convection. J. Climate, 12, 2397-2418.

Jones, C., D. E. Waliser, J. K. E. Schemm, and W. K. M. Lau, 2000: Prediction skill of the Madden and Julian oscillation in dynamical extended range forecasts. Climate Dyn., 16, 273-289.

—, L. M. V. Carvalho, R. W. Higgins, D. E. Waliser, and J. K. E. Schemm, 2004: A statistical forecast model of tropical intraseasonal convective anomalies. J. Climate, 17, 2078-2095.

Kalnay, E., and Coauthors, 1996: The NCEP/NCAR 40-Year Reanalysis Project. Bull. Amer. Meteor. Soc., 77, 437-471.

Kemball-Cook, S., B. Wang, and X. Fu, 2002: Simulation of the intraseasonal oscillation in the ECHAM-4 model: The impact of coupling with an ocean model. J. Atmos. Sci., 59,1433-1453.

Kessler, W. S., 2001: EOF representations of the Madden-Julian oscillation and its connection with ENSO. J. Climate, 14, 30553061.
Khairoutdinov, M. F., and D. A. Randall, 2001: A Cloud Resolving Model as a Cloud Parameterization in the NCAR Community Climate System Model: Preliminary Results. Geophys. Res. Lett., 28, 3617-3620.

,-- , and C. DeMott, 2005: Simulations of the atmospheric general circulation using a cloud-resolving model as a superparameterization of physical processes. J. Atmos. Sci., 62, 2136-2154.

Kiladis, G. N., and K. M. Weickmann, 1992: Circulation anomalies associated with tropical convection during northern winter. Mon. Wea. Rev., 120, 1900-1923.

- K. H. Straub, and P. T. Haertel, 2005: Zonal and vertical structure of the Madden-Julian oscillation. J. Atmos. Sci., 62 , 2790-2809.

Knutson, T. R., and K. M. Weickmann, 1987: 30-60-day atmospheric oscillations: Composite life cycles of convection and circulation anomalies. Mon. Wea. Rev., 115, 1407-1436.

Kummerow, C., and Coauthors, 2000: The status of the Tropical Rainfall Measuring Mission (TRMM) after two years in orbit. J. Appl. Meteor., 39, 1965-1982.

Lau, N.-C., and K.-M. Lau, 1986: The structure and propagation of intraseasonal oscillations appearing in a GFDL general circulation model. J. Atmos. Sci., 43, 2023-2047.

Lau, W. K.-M. and D. E. Waliser, Eds., 2005: Intraseasonal Variability of the Atmosphere-Ocean Climate System. Springer, $474 \mathrm{pp}$.

Lee, M. I., I.-S. Kang, J. K. Kim, and B. E. Mapes, 2001: Influence of cloud-radiation interaction on simulating tropical intraseasonal oscillation with an atmospheric general circulation model. J. Geophys. Res., 106, 14 219-14 233.

,-- , and B. E. Mapes, 2003: Impacts of cumulus convection parameterization on aqua-planet AGCM simulations of tropical intraseasonal variability. J. Meteor. Soc. Japan, 81, 963-992.

Liebmann, B., and C. A. Smith, 1996: Description of a complete (interpolated) outgoing longwave radiation dataset. Bull. Amer. Meteor. Soc., 77, 1275-1277.

— , H. H. Hendon, and J. D. Glick, 1994: The relationship between tropical cyclones of the western Pacific and Indian Oceans and the Madden-Julian oscillation. J. Meteor. Soc. Japan, 72, 401-412.

Lin, J.-L., B. Mapes, M. Zhang, and M. Newman, 2004: Stratiform precipitation, vertical heating profiles, and the Madden-Julian oscillation. J. Atmos. Sci., 61, 296-309.

— , and Coauthors, 2006: Tropical intraseasonal variability in 14 IPCC AR4 climate models. Part I: Convective signals. J. Climate, 19, 2665-2690.

—, M.-I. Lee, D. Kim, I.-S. Kang, and D. M. W. Frierson, 2008: The impacts of convective parameterization and moisture triggering on AGCM-simulated convectively coupled equatorial waves. J. Climate, 21, 883-909.

Liu, P., B. Wang, K. R. Sperber, T. Li, and G. A. Meehl, 2005: MJO in the NCAR CAM2 with the Tiedtke convective scheme. J. Climate, 18, 3007-3020.

Lo, F., and H. H. Hendon, 2000: Empirical extended-range prediction of the Madden-Julian oscillation. Mon. Wea. Rev., 128, 2528-2543.

Madden, R. A., and P. R. Julian, 1971: Detection of a 40-50 day oscillation in the zonal wind in the tropical Pacific. J. Atmos. Sci., 28, 702-708.

, and - 1972: Description of global-scale circulation cells in the tropics with a 40-50 day period. J. Atmos. Sci., 29, 1109-1123.

_, and _- 1994: Observations of the 40-50-day tropical oscillation-A review. Mon. Wea. Rev., 122, 814-837. 
Maloney, E. D., 2002: An intraseasonal oscillation composite life cycle in the NCAR CCM3.6 with modified convection. J. Climate, 15, 964-982.

— in a composite life cycle of the Madden-Julian oscillation. J. Climate, 11, 2387-2403.

$\longrightarrow$, and $-2000 \mathrm{a}$ : Modulation of hurricane activity in the Gulf of Mexico by the Madden-Julian oscillation. Science, 287, 2002-2004.

$\longrightarrow$, and - 2000b: Modulation of eastern North Pacific hurricanes by the Madden-Julian oscillation. J. Climate, 13, 14511460.

- and - 2001: The sensitivity of intraseasonal variability in the NCAR CCM3 to changes in convective parameterization. J. Climate, 14, 2015-2034.

Marshall, A. G., O. Alves, and H. H. Hendon, 2008: An enhanced moisture convergence-evaporation feedback mechanism for MJO air-sea interaction. J. Atmos. Sci., 65, 970-986.

Matthews, A. J., B. J. Hoskins, J. M. Slingo, and M. Blackburn, 1996: Development of convection along the SPCZ within a Madden-Julian oscillation. Quart. J. Roy. Meteor. Soc., 122, 669-688.

Miura, H., M. Satoh, T. Nasuno, A. T. Noda, and K. Oouchi, 2008: Madden-Julian oscillation event realistically simulated by a global cloud-resolving model. Science, 318, 1763-1765, doi:10.1126/science.1148443.

Moorthi, S., and M. J. Suarez, 1992: Relaxed Arakawa-Schubert: A parameterization of moist convection for general circulation models. Mon. Wea. Rev., 120, 978-1002.

Morita, J., Y. N. Takayabu, S. Shige, and Y. Kodama, 2006: Analysis of rainfall characteristics of the Madden-Julian oscillation using TRMM satellite data. Dyn. Atmos. Oceans, 42, 107-126.

Myers, D., and D. E. Waliser, 2003: Three-dimensional water vapor and cloud variations associated with the Madden-Julian oscillation during Northern Hemisphere winter. J. Climate, 16, 929-950.

Neale, R. B., J. H. Richter, and M. Jochum, 2008: The impact of convection on ENSO: From a delayed oscillator to a series of events. J. Climate, 21, 5904-5924.

Nordeng, T. E., 1994: Extended versions of the convective parametrization scheme at ECMWF and their impact on the mean and transient activity of the model in the tropics. ECMWF Tech. Memo. 206, 41 pp.

Numaguti, A., M. Takahashi, T. Nakajima, and A. Sumi, 1995: Development of an atmospheric general circulation model. Climate System Dynamics and Modelling, Vol. I-3, T. Matsuno, Ed., Center for Climate System Research, 1-27.

Rienecker, M. M., and Coauthors, 2008: The GEOS-5 data assimilation system: Documentation of versions 5.0.1, 5.1.0, and 5.2.0. Technical Rep. Series on Global Modeling and Data Assimilation, NASA Tech. Rep. 104606, Vol. 27, 101 pp.

Roeckner, E., and Coauthors, 1996: The atmospheric general circulation model ECHAM-4: Model description and simulation of present-day climate. MPI Rep. 218, 94 pp. [Available online at http://www.mpimet.mpg.de/fileadmin/publikationen/ Reports/MPI-Report_218.pdf.]

Rui, H., and B. Wang, 1990: Development characteristics and dynamic structure of tropical intraseasonal convective anomalies. J. Atmos. Sci., 47, 357-379.

Salby, M. L., and H. H. Hendon, 1994: Intraseasonal behavior of clouds, temperature, and motion in the tropics. J. Atmos. Sci., 51, 2207-2224.
_, R. R. Garcia, and H. H. Hendon, 1994: Planetary-scale circulations in the presence of climatological and wave-induced heating. J. Atmos. Sci., 51, 2344-2367.

Sausen, R., K. Barthel, and K. Hasselmann, 1988: Coupled oceanatmosphere models with flux correction. Climate Dyn., 2, $145-163$.

Schumacher, C., and R. A. Houze Jr., 2003: Stratiform rain in the tropics as seen by the TRMM Precipitation Radar. J. Climate, 16, 1739-1756.

Seo, K. H., J. K. E. Schemm, C. Jones, and S. Moorthi, 2005: Forecast skill of the tropical intraseasonal oscillation in the NCEP GFS dynamical extended range forecasts. Climate Dyn., 25, 265-284.

Slingo, J. M., and Coauthors, 1996: Intraseasonal oscillations in 15 atmospheric general circulation models: Results from an AMIP diagnostic subproject. Climate Dyn., 12, 325-357.

Sperber, K. R., 2003: Propagation and the vertical structure of the Madden-Julian oscillation. Mon. Wea. Rev., 131, 30183037.

2004: Madden-Julian variability in NCAR CAM2.0 and CCSM2.0. Climate Dyn., 23, 259-278.

— , and H. Annamalai, 2008: Coupled model simulations of boreal summer intraseasonal (30-50 day) variability. Part I: Systematic errors and caution on use of metrics. Climate Dyn., 31, 345-372.

—_, and D. E. Waliser, 2008: New approaches to understanding, simulating, and forecasting the Madden-Julian oscillation. Bull. Amer. Meteor. Soc., 89, 1917-1920.

_ J. M. Slingo, and H. Annamalai, 2000: Predictability and the relationship between subseasonal and interannual variability during the Asian summer monsoon. Quart. J. Roy. Meteor. Soc., 126, 2545-2574.

— S. Gualdi, S. Legutke, and V. Gayler, 2005: The MaddenJulian oscillation in ECHAM4 coupled and uncoupled general circulation models. Climate Dyn., 25, 117-140.

— , and Coauthors, 2008: Coarse-resolution models only partly cloudy. Science, 320, 612-613, doi:10.1126/science.320.5876.612a.

Takayabu, Y. N., T. Iguchi, M. Kachi, A. Shibata, and H. Kanzawa, 1999: Abrupt termination of the 1997-98 El Niño in response to a Madden-Julian oscillation. Nature, 402, 279-282.

Thayer-Calder, K., 2008: The role of moisture in the MJO: A comparison of tropical convection processes in the CAM and super-parameterized CAM. M.S. thesis, Department of Atmospheric Science, Colorado State University, $74 \mathrm{pp}$.

, and D. A. Randall, 2009: The role of convective moistening in the Madden-Julian Oscillation. J. Atmos. Sci., in press.

Tian, B. J., D. E. Waliser, E. Fetzer, B. Lambrigtsen, Y. Yung, and B. Wang, 2006: Vertical moist thermodynamic structure and spatial-temporal evolution of the Madden-Julian oscillation in AIRS observations. J. Atmos. Sci., 63, 24622485.

Tiedtke, M., 1989: A comprehensive mass flux scheme for cumulus parameterization in large-scale models. Mon. Wea. Rev., 117, 1779-1800.

Tokioka, T., K. Yamazaki, A. Kitoh, and T. Ose, 1988: The equatorial 30-60-day oscillation and the Arakawa-Schubert penetrative cumulus parameterization. J. Meteor. Soc. Japan, 66, 883-901.

Uppala, S. M., and Coauthors, 2005: The ERA-40 re-analysis. Quart. J. Roy. Meteor. Soc., 131, 2961-3012.

Vitart, F., S. Woolnough, M. A. Balmaseda, and A. M. Tompkins, 2007: Monthly forecast of the Madden-Julian oscillation using a coupled GCM. Mon. Wea. Rev., 135, 2700-2715. 
Waliser, D. E., 2006a: Intraseasonal variability. The Asian Monsoon, B. Wang, Ed., Springer, 203-258.

- 2006b: Predictability of tropical intraseasonal variability. Predictability of Weather and Climate, T. Palmer and R. Hegedorn, Eds., Cambridge University Press, 275-305.

_, K. M. Lau, and J.-H. Kim, 1999: The influence of coupled sea surface temperatures on the Madden-Julian oscillation: A model perturbation experiment. J. Atmos. Sci., 56, 333-358.

— , and Coauthors, 2003: AGCM simulations of intraseasonal variability associated with the Asian summer monsoon. Climate Dyn., 21, 423-446.

Wang, B., 1988: Dynamics of tropical low-frequency waves: An analysis of the moist Kelvin wave. J. Atmos. Sci., 45, 2051-2065.

Wang, W. Q., and M. E. Schlesinger, 1999: The dependence on convection parameterization of the tropical intraseasonal oscillation simulated by the UIUC 11-layer atmospheric GCM. J. Climate, 12, 1423-1457.

— S. Saha, H. L. Pan, S. Nadiga, and G. White, 2005: Simulation of ENSO in the new NCEP Coupled Forecast System Model (CFS03). Mon. Wea. Rev., 133, 1574-1593.

Weickmann, K. M., G. R. Lussky, and J. E. Kutzbach, 1985: Intraseasonal (30-60 day) fluctuations of outgoing longwave radiation and 250-mb streamfunction during northern winter. Mon. Wea. Rev., 113, 941-961.

Wheeler, M., and G. N. Kiladis, 1999: Convectively coupled equatorial waves: Analysis of clouds and temperature in the wavenumber-frequency domain. J. Atmos. Sci., 56, 374-399.

, and K. M. Weickmann, 2001: Real-time monitoring and prediction of modes of coherent synoptic to intraseasonal tropical variability. Mon. Wea. Rev., 129, 2677-2694.

, and H. H. Hendon, 2004: An all-season real-time multivariate MJO index: Development of an index for monitoring and prediction. Mon. Wea. Rev., 132, 1917-1932.
__- and J. L. McBride, 2005: Australian-Indonesian monsoon. Intraseasonal Variability in the Atmosphere-Ocean Climate System, W. K. M. Lau and D. E. Waliser, Eds., Springer, 125-173.

Xie, P. P., and P. A. Arkin, 1997: Global precipitation: A 17-year monthly analysis based on gauge observations, satellite estimates, and numerical model outputs. Bull. Amer. Meteor. Soc., 78, 2539-2558.

Yasunari, T., 1979: Cloudiness fluctuations associated with the Northern Hemisphere summer monsoon. J. Meteor. Soc. Japan, 57, 227-242.

Yu, L., and R. A. Weller, 2007: Objectively analyzed air-sea heat fluxes for the global ice-free oceans. Bull. Amer. Meteor. Soc., 88, 527-539.

Zhang, C., 2005: The Madden-Julian oscillation. Rev. Geophys., 43, RG2003, doi:10.1029/2004RG000158.

-, M. Dong, S. Gualdi, H. H. Hendon, E. D. Maloney, A. Marshall, K. R. Sperber, and W. Wang, 2006: Simulations of the Madden-Julian oscillation in four pairs of coupled and uncoupled global models. Climate Dyn., 27, 573-592, doi:10.1007/ s00382-006-0148-2.

Zhang, G. J., and N. A. McFarlane, 1995: Sensitivity of climate simulations to the parameterization of cumulus convection in the Canadian Climate Centre general circulation model. Atmos.-Ocean, 33, 407-446.

_ and M. Mu, 2005a: Simulation of the Madden-Julian oscillation in the NCAR CCM3 using a revised Zhang-McFarlane convection parameterization scheme. J. Climate, 18, 40464064. , and - 2005b: Effects of modifications to the ZhangMcFarlane convection parameterization on the simulation of the tropical precipitation in the National Center for Atmospheric Research Community Climate Model, version 3. J. Geophys. Res., 110, D09109, doi:10.1029/2004JD005617. 